\title{
LOGROS Y DESAFÍOS DE LA POLÍTICA HABITACIONAL EN CHILE*
}

\author{
José Miguel Simian
}

El presente trabajo se propone mostrar cómo ha evolucionado la situación habitacional en Chile, describir los instrumentos de política habitacional usados en las últimas décadas y las transformaciones que han sufrido, y evaluar si esos instrumentos son útiles para resolver los problemas actuales del mercado habitacional. El trabajo presenta a su vez una estimación cuantitativa tanto de la falta de movilidad habitacional como de la calidad del stock de viviendas.

Este trabajo no considera los efectos del terremoto que azotó Chile en febrero de 2010. Sin embargo, se sostiene que los principales problemas detectados de la política habitacional persistirán si no se hacen cambios en ella, independientemente de la situación generada por el sismo que, sin duda alguna, implicará desafíos adicionales para la política habitacional.

Palabras clave: política habitacional; vivienda social; movilidad habitacional.

José Miguel Simian. Diplom-Kaufmann y Doctor en Economía por la Westfälische Wilhelms-Universität Münster, Alemania. Actualmente es Director Académico y Profesor Asociado del ESE (Escuela de Negocios) de la Universidad de los Andes, Santiago de Chile. Correo electrónico: jsimian@uandes.cl.

* Agradezco los valiosos comentarios de Hernán Román y de un árbitro anónimo de Estudios Públicos. Todos los errores son de mi exclusiva responsabilidad.

Estudios Públicos, 117 (verano 2010). 


\section{Introducción}

$\mathrm{D}$

esde hace ya varias décadas que en nuestro país se hace un importante esfuerzo por mejorar las condiciones habitacionales de la población, especialmente aquellas de los sectores de menores ingresos, al punto que hoy dos de cada tres viviendas que se construyen, son levantadas con ayuda del Estado a través de distintos programas de subsidio habitacional. Sin embargo, la política habitacional chilena de los últimos 40 años no ha sufrido grandes cambios, mientras que las condiciones de vida en el país han cambiado sustancialmente. Se suma a lo anterior el hecho que estas políticas están siendo causa de importantes externalidades en las zonas urbanas. En efecto, la construcción de barrios completos y la expansión de las ciudades por la política habitacional están afectando no sólo la calidad de vida de los beneficiarios de esas políticas sino también la del resto de los habitantes de las respectivas ciudades.

Esta situación ha sido objeto de un intenso debate en los últimos años que se ha centrado en los problemas de la actual política habitacional chilena. ¿Cuáles son estos problemas? En primer lugar, se ha producido una segregación de muchos hogares beneficiarios de viviendas sociales, que han quedado en los extremos de los centros urbanos e incurren en altos costos de transporte para llegar a lugares de trabajo, educación y recreación. Además esta segregación predispone la aparición de bolsones de pobreza y delincuencia en los sectores donde están las viviendas, disminuyendo la calidad de vida de muchas familias ${ }^{1}$. En segundo lugar, existe un problema de baja movilidad habitacional en Chile que, como mostraremos, es en parte resultado de la propia política habitacional ${ }^{2}$. Esto quiere decir que hay un número importante de familias que quisieran cambiarse de vivienda y no pueden hacerlo o les resulta excesivamente costoso ${ }^{3}$. Un tercer elemento del debate es la falta de calidad de las viviendas en Chile, especialmente de aquellas

${ }^{1}$ En esta discusión se centran las contribuciones de Rodríguez y Sugranyes (2004), Rodríguez y Sugranyes (2005a), Hidalgo (2007), Sabatini, Cáceres y Cerda (2001), así como Peterman (2006) y Tokman (2006).

2 Entre las contribuciones a esta discusión se cuentan Herrera (2007) y Herrera/ Valenzuela (2003).

${ }^{3}$ De acuerdo a una encuesta realizada por Rodríguez y Sugranyes (2004), casi un $65 \%$ de los hogares encuestados y que viven en viviendas sociales preferiría cambiar de vivienda. 
construidas a través de los distintos programas de política habitacional $^{4}$. La falta de calidad se traduce en viviendas demasiado pequeñas - lo cual ha venido siendo mejorado en los nuevos programas de vivienda del MINVU y el hacinamiento ha disminuido- y se reflejaría también en bajos niveles de materialidad de las viviendas ${ }^{5}$.

El presente trabajo se inserta en este debate. Su propósito es mostrar cómo ha evolucionado la situación habitacional en Chile, describir los instrumentos de política habitacional usados en las últimas décadas y las transformaciones que han sufrido, y evaluar si esos instrumentos son útiles para resolver los problemas actuales del mercado habitacional. El principal aporte de este trabajo está en la estimación cuantitativa tanto de la falta de movilidad habitacional como de la calidad del stock de viviendas.

Los principales resultados de este trabajo muestran que en las últimas décadas el stock de viviendas ha crecido por sobre el crecimiento de la población, adaptándose a las necesidades de hogares con menos personas, y que el déficit habitacional cuantitativo se ha reducido de manera notoria. La calidad de las viviendas, en cuanto a espacio por habitante, pareciera haber aumentado — no existe en Chile la información de metros cuadrados disponibles por habitante-, reflejándose esto en menores niveles de hacinamiento de los hogares. La mayor parte de la población es además propietaria de la vivienda que ocupa, para lo cual ha contribuido de manera fundamental la política habitacional. Es posible concluir, por tanto, que hemos avanzado significativamente en materia habitacional en los últimos 40 años.

Además, se muestra empíricamente que la "movilidad habitacional" ha disminuido y que son precisamente aquellos hogares que han sido beneficiarios de la política habitacional los que se mueven menos, constatándose así un efecto inmovilizador de la política habitacional en Chile. Pareciera que el mercado habitacional para viviendas de bajo precio (menos de $1.000 \mathrm{UF}$ ) funciona de manera poco eficiente, lo que dificulta la movilidad de los hogares en ese segmento, debido probablemente a la presencia de altos costos de transacción y otras barreras. Sin embargo, no sabemos exactamente qué pasa en ese mercado.

\footnotetext{
${ }^{4}$ Véase lo expresado por la propio autoridad en MINVU (2004), p. 300 y también Rodríguez y Sugranyes (2005b).

${ }^{5}$ Véase por ejemplo Rodríguez y Sugranyes (2004), p. 224.
} 
Se muestra también que la calidad de las viviendas ocupadas por los hogares de menores ingresos, medida a través de su materialidad y del estado de conservación de los materiales, es menor que la calidad de aquellas viviendas ocupadas por el resto de los hogares. Sin embargo, las viviendas sociales o con subsidio de hogares de ingresos bajos son mejores que aquellas de los hogares que no recibieron subsidio. En ese sentido la política habitacional ha sido capaz de mejorar las viviendas de un grupo importante de familias en Chile.

Una de las principales conclusiones de este trabajo es que no necesitamos instrumentos de política habitacional para seguir expandiendo el stock de viviendas, como los que hemos usado hasta ahora, sino instrumentos que permitan mejorar el stock existente y que permitan que el mercado habitacional para viviendas de bajo precio funcione mejor.

Este trabajo se estructura de la siguiente manera: luego de esta introducción, se aborda la situación del mercado habitacional en Chile, la evolución del stock de viviendas, la participación en éste de los programas habitacionales del MINVU y el déficit habitacional. En la sección 3 se discute el problema del racionamiento de crédito y el efecto que tiene sobre políticas que buscan proveer a los hogares de vivienda propia. En la sección 4 se resumen los programas de fomento de la vivienda más tradicionales que se han utilizado en Chile en las últimas décadas. Luego se abordan los cambios en la política habitacional a partir de 2000 y lo que se ha llamado la Nueva Política Habitacional (sección 5). La sección 6 aborda los problemas de segregación, movilidad habitacional y calidad de las viviendas, y si las políticas actuales los solucionan. Se plantean también algunas ideas para mejorar la actual política habitacional. Al final se resumen las principales conclusiones del trabajo.

Parece oportuno señalar que este trabajo no considera los efectos del terremoto que azotó Chile en febrero de 2010. Como quedará claro más adelante, los principales problemas detectados de la política habitacional en Chile persistirán si no se hacen cambios en ella, independientemente de la situación generada por el severo sismo y que, sin duda alguna, implicará desafíos adicionales para la política habitacional chilena.

\section{Situación habitacional en Chile}

Esta sección describe la actual situación habitacional en Chile y su evolución en las décadas pasadas, enfatizando la evolución del stock 
habitacional, la edificación de viviendas nuevas y el papel jugado por la política habitacional. Se aborda también el debate acerca del déficit habitacional.

La Tabla No 1 contiene la información básica acerca de la vivienda en Chile. La cifra fidedigna más reciente acerca del stock habitacional es la del Censo de Población y Vivienda 2002. En ese año había en el país casi 4 millones de viviendas. La tabla presenta además los stocks de vivienda de acuerdo a los distintos censos realizados desde 1952. Como se puede observar, el stock de viviendas viene aumentando a la par con la población en los últimos 50 años. Como el último Censo realizado tiene ya 7 años de antigüedad, se hizo una proyección del stock de viviendas a febrero de 2010. Para ello se sumó al stock de 1992 la construcción realizada entre ese año y 2009 (medida a través de los permisos de construcción de viviendas nuevas) y se supuso una

TABLA N ${ }^{\circ}$ 1: $\quad$ SITUACIÓN HABITACIONAL EN CHILE

\begin{tabular}{|c|c|c|c|c|c|c|c|}
\hline & 1952 & 1960 & 1970 & 1982 & 1992 & 2002 & $2010^{(1)}$ \\
\hline Viviendas (miles) & 1.091 & 1.389 & 1.860 & 2.522 & 3.370 & 3.899 & 4.394 \\
\hline $\begin{array}{l}\text { Viv. permanentes (miles) } \\
\% \text { de viv. permanentes }\end{array}$ & $\begin{array}{r}955 \\
87,5\end{array}$ & $\begin{array}{r}1.159 \\
83,4\end{array}$ & $\begin{array}{r}1.530 \\
82,3\end{array}$ & $\begin{array}{r}2.078 \\
82,4\end{array}$ & $\begin{array}{r}2.826 \\
83,9\end{array}$ & $\begin{array}{r}3.744 \\
96,0\end{array}$ & \\
\hline $\begin{array}{l}\text { Viviendas permanentes } \\
\text { habitadas por propietario } \\
\text { (miles) } \\
\%\end{array}$ & $\begin{array}{r}312 \\
32,7\end{array}$ & $\begin{array}{r}503 \\
43,4\end{array}$ & $\begin{array}{r}829 \\
54,2\end{array}$ & $\begin{array}{r}1.439 \\
69,3\end{array}$ & $\begin{array}{r}1.976 \\
69,9\end{array}$ & $\begin{array}{r}2.827 \\
75,5\end{array}$ & \\
\hline $\begin{array}{l}\text { Población (miles) } \\
\text { Habitantes/vivienda }\end{array}$ & $\begin{array}{r}5.933 \\
5,4\end{array}$ & $\begin{array}{r}7.375 \\
5,3\end{array}$ & $\begin{array}{r}8.885 \\
4,8\end{array}$ & $\begin{array}{r}11.330 \\
4,5\end{array}$ & $\begin{array}{r}13.348 \\
4,0\end{array}$ & $\begin{array}{r}15.116 \\
3,9\end{array}$ & $\begin{array}{r}17.171^{(2)} \\
3,9\end{array}$ \\
\hline $\begin{array}{l}\text { Hacinamiento (\% de vivien } \\
\text { medio ( }>=2.5 \text { hab/dormitorio) } \\
\text { crítico ( }>=5 \text { hab/dormitorio) } \\
\text { sin dormitorio uso exclusivo }\end{array}$ & & & & & $\begin{array}{r}20,7 \\
4,6 \\
4,0\end{array}$ & $\begin{array}{r}12,6 \\
1,1 \\
1,6\end{array}$ & $\begin{array}{r}11,0 \\
1,0 \\
1,2\end{array}$ \\
\hline & & $52-60$ & $60-70$ & $70-82$ & $82-92$ & $92-02$ & $02-10$ \\
\hline $\begin{array}{l}\text { Aumentos en el stock de } \\
\text { viviendas }(\%)^{(4)} \\
\text { de viviendas permanentes (\%) } \\
\text { de la población (\%) }\end{array}$ & & $\begin{array}{l}3,06 \\
2,45 \\
2,76\end{array}$ & $\begin{array}{l}2,96 \\
2,82 \\
1,88\end{array}$ & $\begin{array}{l}2,57 \\
2,58 \\
2,05\end{array}$ & $\begin{array}{l}2,94 \\
3,12 \\
1,65\end{array}$ & $\begin{array}{l}1,47 \\
2,85 \\
1,25\end{array}$ & 1,51 \\
\hline
\end{tabular}

(1) La estimación a febrero de 2010 según detalle en el texto.

(2) La población a 2010 según Naciones Unidas.

(3) Horst (2008) en base a CASEN 2006. En 2002 aparecen cifras de 2003 y en 2010 de 2006.

(4) Tasa de variación promedio anual entre los períodos indicados.

Fuente: INE (1992, 1993) y http://www.ine.cl. 
depreciación del stock existente de $2 \%$ al año ${ }^{6}$. De esta manera se obtiene un stock proyectado al 2010 de casi 4,4 millones de viviendas, una cifra razonable si se compara con los 4,4 millones de viviendas que había en Chile en 2006 de acuerdo a la encuesta CASEN ${ }^{7}$.

El stock habitacional creció entre 1952 y 2002 a una tasa promedio anual de 2,6\%. En este lapso la cantidad total de viviendas se multiplicó por un factor de 4,1, mientras que la población lo ha hecho por un factor de sólo 2,9. Esto responde a la reducción en el tamaño de los hogares, y se refleja en el índice de habitantes por vivienda que estaba sobre 5 personas en 1952 y que hoy está en 3,8 con una tendencia a seguir descendiendo, como se observa también en otros países del mundo.

Lamentablemente ni la encuesta CASEN ni el Censo contienen información del número de metros cuadrados disponibles por habitante, que es la cifra usada internacionalmente para medir un aspecto de la calidad de las viviendas. Sólo disponemos de información respecto del nivel de hacinamiento. Como se aprecia en la Tabla $\mathrm{N}^{\circ} 1$, ha habido una reducción en el hacinamiento dentro de las viviendas, medido a través del número de dormitorios disponibles por persona. El porcentaje de hogares en hacinamiento medio se ha reducido casi a la mitad entre 1992 y 2006, y el hacinamiento crítico se ha reducido fuertemente también hasta llegar a un 1\% de las viviendas.

La expansión del stock habitacional no ha sido constante en las últimas décadas. En efecto, la Tabla $\mathrm{N}^{\circ} 1$ muestra que los años comprendidos entre 1952 y 1970 y luego entre 1982 y 1992 la expansión del stock habitacional fue de aproximadamente 3\% por año. La excepción la representa el período comprendido entre 1970 y 1982, en el cual el país enfrenta dos profundas recesiones. En esos años, el ritmo de expansión del stock habitacional se redujo en casi medio punto porcentual. En el período comprendido entre 1992 y 2002, la tasa de crecimiento del stock habitacional se reduce todavía más, pero manteniendo un nivel de construcción de viviendas nuevas sobre las 100.000 unidades por año. Especialmente destacable es el período entre 1982 y 1992 donde el aumento de la vivienda casi duplica el aumento de la población.

${ }^{6}$ Esta tasa de depreciación se estima según la descripción más abajo. Véase sección

${ }^{7}$ Estas cifras no consideran el efecto del terremoto de febrero de 2010 en el stock de viviendas en Chile. 
El Gráfico No 1 muestra la evolución de los permisos de edificación en Chile entre 1960 y 2008. Puede apreciarse que la construcción de viviendas está fuertemente ligada al ciclo económico. Sin embargo, las fluctuaciones en las nuevas edificaciones son atribuibles en mayor medida a la edificación privada, ya que la construcción de viviendas sociales es más estable ${ }^{8}$. En los últimos 50 años se distinguen claramente dos etapas: la primera de ellas corresponde al período comprendido entre 1960 y 1982 que se caracteriza por un movimiento más bien errático de la construcción de viviendas nuevas con fluctuaciones muy grandes. En ese lapso el PIB real creció a una tasa promedio anual de 2,9\% y se construyeron en promedio 37.000 viviendas por año. La segunda etapa, entre 1983 y 2008 está caracterizada por un crecimiento promedio del producto real de 5,6\% y una construcción promedio

GRÁFICO No 1 : $\quad$ PERMISOS DE EDIFICACIÓN (MILES)

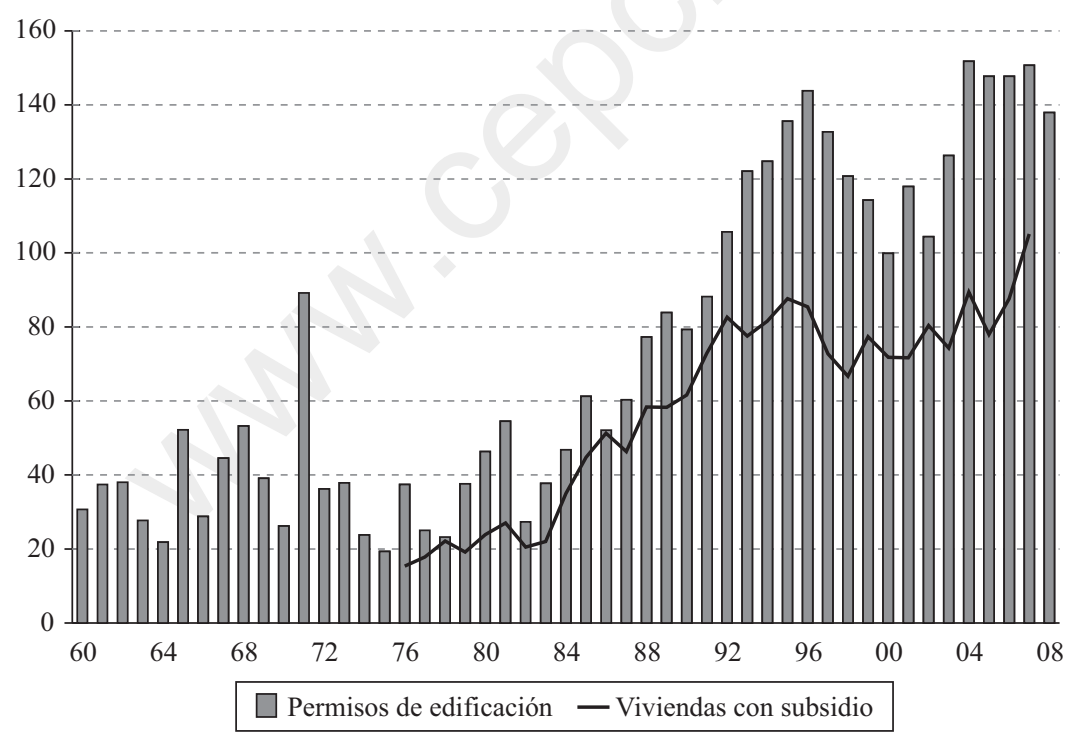

Fuente: Elaboración propia en base a INE, Compendio Estadístico (varios años), e información de subsidios pagados y viviendas terminadas, disponible en http:// www.observatoriohabitacional.cl.

${ }^{8}$ Así por ejemplo entre 1990 y 2007 el promedio de construcción de viviendas con subsidio fue de aprox. 79.000 unidades con una desviación estándar de 9.900 viviendas, mientras que el promedio de la edificación de viviendas sin subsidio fue de 43.000 con una desviación estándar de 16.000 viviendas. La variabilidad viene, por lo tanto, sobre todo de la edificación privada. 
de 106.000 viviendas nuevas por año. Este auge de la construcción permite explicar el fuerte incremento del stock de viviendas por sobre el aumento de la población en el período entre 1982 y 1992. Esta segunda etapa tampoco es completamente pareja en cuanto a nuevas edificaciones $\mathrm{y}$, como se aprecia en la Tabla $\mathrm{N}^{\circ} 1$, la década entre 1992 y 2002 es más floja que la anterior y el stock habitacional se expande a la mitad de la velocidad. A partir de 1997 se aprecia un brusco descenso en los permisos de edificación que caen casi un 30\% entre el peak de 1996 y el año 2000, para luego comenzar a recuperarse y alcanzar cifras record de edificación de viviendas nuevas entre 2004 y 2008. En estos años se construyen aproximadamente 150.000 viviendas nuevas cada año. Así y todo se trata de un incremento de poco más de un 3\% en el stock existente.

El Gráfico No 1 muestra también la importancia de la política habitacional en el aumento en el stock de viviendas. La línea gruesa continua indica el número de viviendas básicas y progresivas terminadas y el número de subsidios del Subsidio Habitacional pagados por año ${ }^{9}$, es decir, refleja el aporte de la política habitacional al incremento del stock de viviendas ${ }^{10}$. Entre 1976 y 2007 las viviendas construidas con subsidios, o bien como parte de los programas de Vivienda Básica y Progresiva, fueron en promedio un 67\% de los permisos de edificación. Es decir, más o menos 2 de cada 3 viviendas se construyen amparadas bajo algún programa de subsidio habitacional.

Dos aspectos adicionales de la evolución del mercado habitacional chileno merecen especial mención. En primer lugar, Chile muestra una tasa de ocupación de la vivienda propia que llega al 76\% en 2002. Entre 1952 y 1980 esta tasa aumentó considerablemente, en 1970 estaba casi en un 55\% y subió en 20 puntos porcentuales más hasta 2002. Hacia ese año se constata que tres de cada cuatro hogares son dueños de la vivienda en la que viven, como se puede apreciar en la Tabla $\mathrm{N}^{\circ} 1$. Esto no sorprende considerando que todos los programas de fomento de la vivienda en Chile estuvieron dirigidos a dar acceso a la vivienda propia, y su participación en la construcción de viviendas

\footnotetext{
${ }^{9}$ No otorgados, ya que no todos los subsidios otorgados se traducen finalmente en la construcción o compra de una vivienda.

${ }^{10}$ Esta comparación adolece del defecto de comparar viviendas con subsidio efectivamente construidas con permisos de edificación que pueden implicar un cierto rezago. Dado que no hay cifras de viviendas terminadas para el país, no es posible hacer una comparación mejor.
} 
nuevas es considerable. Si comparamos la situación chilena con la de otros países, vemos que Chile tiene un nivel de ocupación de su vivienda propia alto. La Tabla $\mathrm{N}^{\circ} 2$ muestra las tasas de ocupación de vivienda propia en varios países de la OECD y algunos de la región. La tasa promedio de ocupación de la vivienda propia de los países considerados de la OECD es de 68\%. Los países del sur de Europa como España, Grecia e Italia muestran una mayor proporción de propietarios, con tasas de ocupación de la vivienda propia sobre el 80\%. Los países del norte en cambio muestran tasas inferiores, pero en general sobre el 50\%. La excepción la constituye Alemania con una tasa de ocupación de vivienda propia de $42 \%$, un nivel extremadamente bajo ${ }^{11}$.

Prácticamente todos los países de América Latina presentan, en cambio, altas tasas de ocupación de la vivienda propia. De acuerdo a Gandelman (2008) el promedio de ocupación de la vivienda propia en la región es de $72 \%$. La Tabla № 2 incluye información sobre Argentina, Brasil y Perú donde los hogares que habitan su vivienda propia están en

TABLA N ${ }^{\circ}$ 2: $\quad$ PORCENTAJE DE HOGARES PROPIETARIOS DE LAS VIVIENDAS QUE OCUPAN (\%)

\begin{tabular}{lccc}
\hline & 1980 & 1990 & $2002 *$ \\
\hline España & 73 & 78 & 85 \\
Grecia & 75 & 76 & 83 \\
Italia & 59 & 68 & 80 \\
Irlanda & 76 & 79 & 77 \\
Australia & 71 & 72 & 70 \\
Reino Unido & 58 & 65 & 69 \\
Estados Unidos & 65 & 64 & 68 \\
Suecia & 58 & 56 & 61 \\
Japón & 60 & 54 & 60 \\
Francia & 47 & 39 & 55 \\
Alemania & 41 & 64,7 & 68,2 \\
\hline Promedio & 62,1 & & 72,6 \\
\hline Argentina & & & 69,3 \\
Brasil & & & 74,2 \\
Perú & & & \\
\hline
\end{tabular}

* Último dato disponible.

Fuente: OECD (2004); Gandelman (2008).

${ }^{11}$ Véanse los trabajos de Simian (2000) y Simian (2004), donde se discuten las causas del bajo nivel de vivienda propia en Alemania en comparación con Chile. 
torno al $70 \%$. Sin embargo, las cifras de hogares que arriendan una vivienda son menores al $15 \%$ en todos los países ${ }^{12}$. El resto ocupa la vivienda con o sin aprobación del propietario. Esto es indicativo de que los mercados habitacionales no funcionan del todo bien y que todavía prevalece un cierto nivel de economía informal en ese mercado.

Destacable es además que la vivienda propia en Chile es transversal a todos los quintiles de ingreso, como se puede apreciar en la Tabla $\mathrm{N}^{\circ}$ 3. En otros países esto dista mucho de ser así. En los Estados Unidos la mitad superior de ingresos (ingresos iguales y superiores a la mediana de ingreso de todos los hogares) vive en más de un $80 \%$ en una vivienda propia, mientras que sólo el $50 \%$ de los hogares con ingresos bajo la mediana de ingresos lo hace ${ }^{13}$. En Alemania ocurre algo similar, donde más del $70 \%$ de los hogares con ingresos superiores a los 4.500 euros ocupa su propia vivienda, mientras que sólo el $30 \%$ de los hogares con ingresos bajo los 2.000 euros vive en una vivienda propia ${ }^{14}$. No cabe duda de que en este resultado ha influido la política habitacional chilena de fomento de la vivienda propia que se ha aplicado de manera sistemática y masiva desde hace ya varias décadas.

TABLA N ${ }^{\circ}$ 3: $\quad$ VIVIENDA PROPIA SEGÚN QUINTIL DE INGRESO (\%)

\begin{tabular}{lrrrrr}
\hline & I & II & III & IV & V \\
\hline Propia pagada & 62,7 & 60,4 & 59,0 & 55,6 & 48,2 \\
Propia pagándose & 5,2 & 9,6 & 9,8 & 13,9 & 20,1 \\
\cline { 2 - 6 } & 67,9 & 69,9 & 68,8 & 69,5 & 68,3 \\
\cline { 2 - 6 } Arrendada con contrato & 3,3 & 6,0 & 8,2 & 9,3 & 14,9 \\
Arrendada sin contrato & 5,6 & 6,0 & 6,1 & 7,7 & 6,3 \\
\cline { 2 - 6 } & 8,9 & 12,0 & 14,3 & 17,0 & 21,2 \\
\hline Cedida por familiar & 18,5 & 13,8 & 12,8 & 9,3 & 7,0 \\
Cedida por servicio & 2,6 & 2,4 & 2,6 & 2,8 & 2,6 \\
Otro & 2,1 & 1,9 & 1,5 & 1,4 & 0,9 \\
Totales & 100,0 & 100,0 & 100,0 & 100,0 & 100,0 \\
\hline
\end{tabular}

Fuente: Elaboración propia en base a CASEN 2006.

${ }^{12}$ Véase Gandelman (2008), p. 6.

${ }^{13}$ Véase información del Census Bureau; Housing Vacancy Survey; http://www.census.gov/hhes/www/housing/hvs/hvs.html.

${ }^{14}$ Véase StBA (2007). 
Un cambio se ha producido también en la calidad de las viviendas en el país. De acuerdo a la evidencia presentada en la Tabla $\mathrm{N}^{\circ} 1$, vemos que entre 1992 y 2002 se da un salto en el número de viviendas permanentes. La proporción de viviendas permanentes sobre el stock total sube de $84 \%$ en 1992 a $96 \%$ en 2002. Esto significa un aumento en más de 300.000 viviendas de mejor calidad. De este modo queda una cifra bastante menor de viviendas que no tienen ese carácter y que pueden considerarse como soluciones habitacionales precarias. A una conclusión similar se puede llegar con las cifras de la encuesta CASEN. De acuerdo a la CASEN 1990, en ese año, un 63,2\% de las viviendas tenía un índice de materialidad "bueno". Este índice sube a $77 \%$ en 2006, reflejando también un aumento sustancial en esos quince años de la calidad de las viviendas en Chile.

Esta primera mirada a la calidad del stock de viviendas no entrega ninguna pista acerca del déficit habitacional. Este último cuantifica la demanda habitacional insatisfecha. Se trata de personas que quieren una vivienda y no han podido acceder a ella ${ }^{15}$. Esto es difícil de medir ya que no hay manera de saber exactamente, dentro del universo de hogares que no tienen una vivienda, quiénes son los que no pueden acceder a ella y quiénes los que sencillamente no quieren una. Además de los requerimientos de viviendas nuevas, las mediciones del déficit habitacional intentan cuantificar también aquellas viviendas que, por el estado en que se encuentran, debieran ser reemplazadas porque, por ejemplo, los techos o muros están en mal estado de conservación, o porque la materialidad de la vivienda es deficiente, como es el caso de mediaguas o viviendas fabricadas con materiales de desecho. Para estos casos se habla de un déficit cualitativo.

Las dos definiciones fundamentales para estimar el déficit o los requerimientos habitacionales son el modo de contabilizar las viviendas en mal estado (el mencionado déficit cualitativo) y el modo de medir los requerimientos de los hogares que están allegados en viviendas de otros hogares (allegamiento externo), o bien, los núcleos familiares ${ }^{16}$,

${ }^{15}$ En estricto rigor no se trata en todos los casos de una demanda real ya que hay hogares que no pueden adquirir una vivienda.

${ }^{16}$ Núcleos allegados son por ejemplo madres (o padres) solteros, parejas o bien adultos mayores que viven junto a otro hogar en una vivienda. Muchas veces hay relaciones de parentesco entre el núcleo familiar allegado y el hogar principal que ocupa la vivienda. Esta forma de allegamiento no necesariamente implica un hacinamiento dentro de la vivienda, especialmente cuando se produce en los quintiles más altos de ingreso. 
que están allegados a algún hogar y comparten la vivienda (allegamiento interno) y, se supone, necesitan una vivienda nueva (déficit cuantitativo).

La Tabla $\mathrm{N}^{\circ} 4$ muestra las estimaciones de déficit habitacional realizadas por el MINVU en base al Censo 2002, por Mideplan en base a la encuesta CASEN 2006, siguiendo las definiciones del MINVU, luego la estimación de la Cámara Chilena de la Construcción (CCHC) en base a sus propias definiciones y utilizando los datos de la encuesta CASEN 2006 y finalmente la estimación de Libertad y Desarrollo (LYD) en Horst (2008), usando la misma encuesta, y en base a sus propias definiciones ${ }^{17}$.

Una diferencia metodológica importante entre el MINVU, la CCHC y LYD radica en que el primero utiliza para su cálculo de viviendas irrecuperables solamente los materiales de los que están construidos los muros. La CCHC y LYD utilizan el tipo de vivienda (para el caso de las casetas sanitarias y mediaguas) y el estado de conservación de los muros, independientemente del material del cual estén hechos. Esto se produce debido a que el MINVU calcula sus requerimientos de vivienda en base al Censo que no contiene información acerca del estado de conservación de los materiales de la vivienda. Los otros dos trabajan

TABLA No 4: $\quad$ DÉFICIT HABITACIONAL (DIFERENTES MEDICIONES)

\begin{tabular}{|c|c|c|c|c|c|c|}
\hline & \multirow{2}{*}{$\begin{array}{r}\text { MINVU } \\
2002\end{array}$} & \multirow{2}{*}{$\begin{array}{l}\text { Mideplan } \\
2006\end{array}$} & \multicolumn{2}{|c|}{ CCHC 2006} & \multicolumn{2}{|c|}{ LYD 2006} \\
\hline & & & Total & $\begin{array}{l}\text { Int. } \\
\text { Social* }\end{array}$ & Total & $\begin{array}{c}\text { Int. } \\
\text { Social* }\end{array}$ \\
\hline $\begin{array}{l}\text { Requerimientos cualitativos } \\
\text { (viviendas en mal estado) }\end{array}$ & 155.631 & 77.930 & 380.520 & 295.234 & 370.413 & 309.270 \\
\hline Hogares secundarios en una viv. & 241.979 & 125.882 & 71.236 & 58.863 & 85.823 & 62.471 \\
\hline Núcleos allegados econon. indepen. & 145.932 & & 421.898 & 152.238 & 474.459 & 313.381 \\
\hline Núcleos secundarios hacinados & 89.450 & 208.537 & & & & \\
\hline Déficit habitacional & 632.992 & 412.349 & 873.654 & 506.335 & 930.695 & 371.741 \\
\hline \% sobre stock de viviendas & 16,2 & 9,5 & 20,1 & 11,7 & 21,5 & 8,6 \\
\hline
\end{tabular}

* Viviendas de interés social, pertenecientes al 60\% más pobre de la población.

Fuentes: MINVU (2004); Horst (2008); CCHC (Cámara Chilena de la Construcción) (2008).

${ }^{17}$ Para una discusión extensa de las metodologías de estimación del déficit habitacional, véase Horst (2008), CCHC (2008) y MINVU (2004). 
en base a la encuesta CASEN que sí contiene información respecto del estado de conservación ${ }^{18}$. Además el MINVU sólo considera como parte del déficit cuantitativo aquellos hogares allegados que viven en una situación de hacinamiento ${ }^{19}$. Los dos segundos, en cambio, los consideran independientemente del nivel de hacinamiento que exista y usan otra metodología para separar el allegamiento voluntario del involuntario ${ }^{20}$. Esto produce las diferencias que se aprecian en la tabla. Mientras que el MINVU considera en 2006 poco menos de 80.000 viviendas como en mal estado, la CCHC y LYD llegan a cifras varias veces superiores.

Es posible concluir que en las últimas décadas se ha producido un sostenido incremento del stock de viviendas en Chile, que ha permitido que la gran mayoría de la población acceda a una solución habitacional. Además de eso, gran parte de las familias en el país ocupan una vivienda propia y esto sucede transversalmente en todos los quintiles de ingreso. También la calidad de las viviendas ha mejorado, reflejándose en un menor porcentaje de viviendas irrecuperables. Por otra parte el

${ }^{18}$ Adicionalmente las tres estimaciones mencionadas consideran como viviendas irrecuperables aquellas del tipo mediaguas, ranchos o chozas y viviendas móviles (como carpas). Esta información está disponible tanto en el Censo como en la encuesta CASEN. La falta de acceso a servicios como agua, luz y alcantarillado no se considera como parte del déficit cualitativo, ya que no implica una necesidad de nuevas viviendas sino solamente dar acceso a esos servicios a la vivienda en cuestión y toda vez que una gran mayoría de las viviendas en el país cuentan con acceso a los servicios básicos. En 2006 sólo un 2,6\% de las viviendas tenía algún problema de saneamiento, es decir, de falta de acceso a alguno de los servicios mencionados.

${ }^{19} \mathrm{El}$ hacinamiento se mide utilizando el número de personas por dormitorio. Se consideran dos niveles de hacinamiento: hacinamiento medio en el caso que en la vivienda vivan más de 2,5 personas por dormitorio y hacinamiento crítico a partir de 5 personas por dormitorio o en caso de que la vivienda no cuente con dormitorios de uso exclusivo.

${ }^{20}$ La CCHC (Cámara Chilena de la Construcción) define el concepto de "tasa natural de allegamiento" como el porcentaje de jefes de núcleos allegados menores de 30 años del mayor decil de ingreso dentro de los hogares de ese decil. Ese porcentaje se aplica luego a todos los deciles para calcular el allegamiento voluntario. Para el año 2006 esta tasa era de $78 \%$. Adicionalmente la CCHC define los requerimientos habitacionales de interés social como aquellos del $60 \%$ más pobre de los hogares (es decir, los quintiles de ingreso I, II y III). LYD lo hace de manera distinta: en el caso de los hogares secundarios (allegamiento externo) contabiliza sólo aquellos de los quintiles de ingreso II a V como potenciales demandantes de nuevas viviendas, ya que, así se supone, los del primer quintil no tienen suficiente capacidad económica. Para el caso de los núcleos secundarios, se desestiman como potenciales demandantes de nuevas viviendas los núcleos secundarios unipersonales (que son en muchos casos personas mayores) y los núcleos secundarios de cualquier tipo del primer quintil de ingresos. 
nivel de hacinamiento de la población en las viviendas ha disminuido significativamente. Esta evolución ha sido acompañada de una muy relevante participación del Estado en el mercado de viviendas. En las siguientes secciones se abordará la necesidad de una política habitacional y las políticas aplicadas en Chile con sus problemas.

\section{El acceso a la vivienda}

El valor de una vivienda sobrepasa tres o cuatro veces el ingreso anual del hogar que la utiliza, lo que lleva a que la compra de una vivienda vaya casi siempre ligada a un financiamiento crediticio y muchos hogares sólo pueden adquirirla mediante un crédito hipotecario ${ }^{21}$. Chiuri/Japelli (2003) mostraron, usando paneles de varios países de la OECD que incluían en total más de 400.000 hogares, que la disponibilidad de crédito hipotecario afecta sustancialmente el acceso a la vivienda propia, especialmente de hogares más jóvenes.

En el mercado de créditos se observa, sin embargo, el fenómeno de racionamiento, es decir, la tasa de interés no lleva la oferta y la demanda a un equilibrio y, dada una cierta tasa de interés de mercado, una parte de la demanda queda insatisfecha. Este fenómeno conocido como racionamiento del crédito tiene su causa en la asimetría de información entre deudores y prestamistas y ha sido ampliamente discutido en la literatura económica ${ }^{22}$. El contrato de crédito es un contrato incompleto, en el que no se pueden estipular medidas a tomar frente a todas las contingencias a ocurrir. Debido a esto el acreedor asume el riesgo de que el deudor no devuelva la suma prestada. Este riesgo tiene la particularidad de estar positivamente correlacionado con la tasa de interés. El aumento de la misma no hace más que aumentar el riesgo que el deudor no devuelva el crédito. Por tanto, la tasa de interés no sirve para seleccionar a los deudores y el acreedor debe utilizar otros mecanismos para disminuir el riesgo del crédito como son garantías, hipotecas, etc. Por lo tanto sólo aquellos deudores que pueden ofrecer garantías a los prestamistas obtienen un crédito.

${ }^{21}$ Un método alternativo es el leasing habitacional en Chile que existe desde 1996. Éste permite adquirir la vivienda mediante el pago de una cuota mensual, en principio sin ningún ahorro propio. Sin embargo no son muchos los hogares en Chile que utilizan este sistema. Véase la sección 4.3.

${ }^{22}$ Véase por ejemplo Jaffe y Russel (1976) o bien Stiglitz y Weiss (1981). 
En los Estados Unidos se buscó una salida a este problema colocando las carteras de créditos de hogares con mayor riesgo de morosidad en bonos securitizados, en el llamado segmento subprime de créditos hipotecarios que tuvieron los problemas conocidos y que gatillaron la crisis financiera internacional en 2007 y $2008^{23}$. Para Chile también se han hecho propuestas similares que no han encontrado eco y hoy en día han perdido aún más fuerza a la luz de los sucesos de la economía norteamericana ${ }^{24}$.

La particularidad de los créditos para financiar la vivienda (por lo general créditos hipotecarios) radica en que están en parte cubiertos por el inmueble a financiar. La institución financiera que otorga un crédito se enfrenta en este caso a dos tipos de riesgo ${ }^{25}$ : el riesgo de cesación de pago y el riesgo de los costos de transacción. El primero podemos definirlo como el riesgo de que el precio del inmueble caiga por debajo del monto del crédito, generando un incentivo para que el deudor deje de pagar. Esto se soluciona limitando el crédito a un 65 y hasta $70 \%$ del valor del inmueble y exigiendo que quien adquiere una vivienda propia cubra los restantes 30 a 35\% del valor del inmueble con ahorros o un crédito personal. Familias de bajos ingresos y sin capacidad de ahorro quedan, por lo tanto, sin acceso al crédito y a la vivienda propia.

El riesgo de los costos de transacción es el riesgo del acreedor de que los costos de liquidación del crédito, es decir, sacar al deudor de la vivienda, venderla, etc., sean mayores que los ingresos que el acreedor ha obtenido con el crédito. Entre estos costos también habría que incluir las pérdidas de intereses mientras dura el procedimiento. Este riesgo es especialmente alto en el caso de los créditos de bajo monto. Estos son de escaso atractivo para las instituciones financieras ya que tienen los mismos costos fijos de otorgamiento que los créditos

${ }^{23}$ Véase el trabajo de Gorton (2009) para una detallada explicación del funcionamiento del segmento subprime y la securitización de los bonos respaldados por hipotecas de ese segmento.

${ }^{24}$ Véase Almarza (1997), donde se propone la securitización de créditos hipotecarios en América Latina pensando específicamente en la compra de los bonos por parte de las AFP. En la medida que el deudor tenga la obligación de pagar, aun cuando el valor de la vivienda descienda por debajo del valor del crédito, y además los créditos no cubran más del 70\% de la vivienda, es decir, haya suficiente ahorro previo, puede ser un buen mecanismo para expandir el crédito hipotecario.

${ }^{25}$ Véase Fallis (1983). 
de montos más altos. Dependiendo del monto del crédito puede que el margen de utilidad resultante no cubra esos $\operatorname{costos}^{26}$.

Considerando lo anterior, una política habitacional con el objetivo de permitir el acceso a la vivienda propia de hogares de menores recursos, debe apuntar al problema de asimetría de información y racionamiento en el mercado crediticio, es decir a solucionar el problema de financiamiento por falta de ahorro. En las secciones que siguen se analizará cómo resuelven esto las políticas aplicadas en Chile.

\section{La política habitacional en Chile}

No es el objetivo de este trabajo presentar en detalle cuál ha sido el desarrollo de las políticas habitacionales chilenas en su historia sino más bien evaluar las políticas aplicadas en los últimos años. Es por esto que aquí se describen en trazos muy gruesos los principales hitos de la política habitacional chilena desde comienzos del siglo XX hasta $1973^{27}$. Se describe con mayor detalle la política habitacional implementada a partir de 1974 y hasta 2000. En la siguiente sección se aborda la llamada Nueva Política Habitacional que se está aplicando desde entonces.

Desde 1906 se aplica en Chile algún tipo de política habitacional. En ese año se crearon los llamados Consejos de Habitaciones con la finalidad de construir viviendas para los sectores de menores recursos de la población. Posteriormente, en 1925, se legisló por primera vez sobre los contratos de arriendo, poniendo un límite a los precios de arriendo para las viviendas de trabajadores. Esta medida benefició a los ocupantes de las viviendas, pero tuvo el inconveniente de reducir la rentabilidad de las inversiones en los inmuebles, agudizando los problemas de déficit habitacional ya existentes. En 1936 los Consejos de Habitaciones fueron reemplazados por la Caja de Habitación Popular que administraba recursos fiscales para la construcción de viviendas sociales. En 1954 se creó la Corporación de la Vivienda (CORVI),

${ }^{26}$ Hace algunos años, esto dio origen en Chile a la entrega por parte del Ministerio de Vivienda y y Urbanismo de un subsidio a los costos de otorgamiento de los créditos.

${ }^{27}$ Véase también Simian (2000). Para la historia previa a 1959 véase Bravo (1959) y para el período entre 1965 y 1990 véase Castañeda (1990). Otros trabajos más recientes son el del propio MINVU (2007), Hidalgo (2005) y Castillo e Hidalgo (2007). 
institución que debía construir y asignar viviendas sociales. La CORVI se mantuvo hasta 1976 y tuvo un impacto importante en la construcción de estas viviendas. En 1965 se crearon varias instituciones más relacionadas con el problema habitacional y el desarrollo urbano. Entre otras se creó ese año el Ministerio de Vivienda y Urbanismo y también la Corporación Habitacional (Corhabit) que apoyaría la gestión de la CORVI. Hasta 1976 la política habitacional se realizó a través de estas dos instituciones. La CORVI tenía asignada la tarea de construcción de viviendas sociales y la Corhabit se dedicaba principalmente a su asignación.

Un avance importante para el financiamiento de la vivienda fue la creación en 1960 del Sistema Nacional de Ahorro y Préstamo (SINAP), que otorgaba créditos hipotecarios de largo plazo y se financiaba mediante depósitos de corto plazo. Este sistema funcionó bien mientras el SINAP gozó del monopolio sobre depósitos reajustables, hasta 1975. En ese año, con la liberalización del mercado financiero chileno, el SINAP perdió la ventaja que tenía hasta entonces y los depositantes comenzaron a migrar a opciones de depósito más rentables. En 1977 se declaró la quiebra de la institución.

El gobierno militar, a partir de 1973, significó un profundo cambio en las políticas económicas aplicadas en Chile, las cuales afectaron también la política habitacional. Los cambios involucraron tanto las instituciones que la diseñaban y aplicaban así como también las mismas políticas. Respecto de los cambios institucionales cabe señalar que en 1976 se reformó el Ministerio de Vivienda y Urbanismo (MINVU), creándose los Servicios Regionales de Vivienda y Urbanismo (SERVIU) así como las Secretarías Regionales del Ministerio (SEREMI). Tanto la CORVI como la Corhabit fueron disueltas. Otro cambio importante fue la introducción de la letra hipotecaria en 1977, que se transformaría en el instrumento más importante del financiamiento de la vivienda en Chile.

Para el fomento de la vivienda social se utilizaron a partir de entonces dos mecanismos de subsidio: el primero es el subsidio a la demanda, dirigido a hogares con capacidad de ahorro y acceso al crédito, que funciona a través de la entrega de un voucher o certificado de subsidio para adquirir una vivienda. Dentro de este mecanismo de subsidio se cuentan el Subsidio General Unificado (SGU), el Programa 
TABLA N ${ }^{\circ}$ 5: $\quad$ PRINCIPALES PROGRAMAS DE SUBSIDIO HABITACIONAL EN CHILE 1974-2008

\begin{tabular}{|c|c|c|c|c|c|c|c|c|c|c|}
\hline $\mathrm{Nr}$ & Nombre & $\begin{array}{l}\text { Modalidad/ } \\
\text { etapa }\end{array}$ & Ley/D.S. & Ahorro & Crédito & $\begin{array}{l}\text { Valor tope } \\
\text { vivienda } \\
\text { (UF) }\end{array}$ & $\begin{array}{l}\text { Monto } \\
\text { ahorro } \\
\text { (UF) }\end{array}$ & $\begin{array}{l}\text { Sub- } \\
\text { sidio } \\
\text { (UF) }\end{array}$ & $\begin{array}{l}\text { Año } \\
\text { inicio }\end{array}$ & $\begin{array}{c}\text { Año } \\
\text { término }\end{array}$ \\
\hline \multirow[t]{3}{*}{1} & \multirow{3}{*}{$\begin{array}{l}\text { Vivienda } \\
\text { Básica }\end{array}$} & SERVIU & D.S. 62/1984 & sí & sí & 230 & 10 & 140 & 1984 & 2002 \\
\hline & & $\begin{array}{c}\text { Libre } \\
\text { elección }\end{array}$ & D.S.159/1994 & sí & sí & 400 & 20 & 140 & 1994 & 2004 \\
\hline & & $\begin{array}{l}\text { Adulto } \\
\text { mayor }\end{array}$ & $\begin{array}{c}\text { D.S. 62/1984, } \\
150 / 90\end{array}$ & sí & sí & 230 & 10 & 140 & 1984 & \\
\hline 2 & \multicolumn{2}{|l|}{$\begin{array}{l}\text { Programa } \\
\text { Especial de } \\
\text { Trabajadores } \\
\text { (PET) }\end{array}$} & D.S. $235 / 1985$ & sí & sí & 400 & 40 & 90 & 1985 & 2004 \\
\hline \multirow[t]{3}{*}{3} & \multirow{3}{*}{$\begin{array}{l}\text { Subsdio } \\
\text { Unificado }\end{array}$} & Primer Tramo & D.S. $188 / 78$ & sí & sí & 500 & 50 & $100 / 120$ & 1988 & $2004^{(1)}$ \\
\hline & & Segundo Tramo & D.S. $188 / 78$ & sí & sí & 1000 & 100 & $80 / 100$ & 1988 & 2004 \\
\hline & & Tercer Tramo & D.S. $188 / 78$ & sí & sí & 1500 & 150 & $80 / 60$ & 1988 & 2004 \\
\hline \multirow[t]{3}{*}{4} & \multirow[t]{3}{*}{$\begin{array}{l}\text { Subsido } \\
\text { Rural }\end{array}$} & $\begin{array}{l}\text { Con sitio } \\
\text { propio }\end{array}$ & $\begin{array}{c}\text { D.S. } 167 / 1986 \text {, } \\
117 / 02\end{array}$ & sí & no & $260 / 400$ & 10 & 170 & 1986 & \\
\hline & & En villorrios & & sí & no & $260 / 400$ & 10 & 200 & 1986 & \\
\hline & & $\begin{array}{c}\text { Saneamiento } \\
\text { sanitario }\end{array}$ & & sí & no & 73 & 3 & 70 & 1980 & \\
\hline \multirow[t]{3}{*}{5} & \multirow{3}{*}{$\begin{array}{l}\text { Vivienda } \\
\text { Progresiva }\end{array}$} & SERVIU & D.S. $140 / 1990$ & sí & no & 140 & 8 & 132 & 1990 & 2003 \\
\hline & & Privada & D.S. $140 / 1990$ & no & no & 140 & $3 / 8$ & & 1990 & 2007 \\
\hline & & $\begin{array}{l}\text { Privada/seg. } \\
\text { Etapa }\end{array}$ & D.S. $140 / 1990$ & sí & no & 70 & 5 & 35 & 1990 & 2007 \\
\hline 6 & \multicolumn{2}{|c|}{$\begin{array}{l}\text { Densificación } \\
\text { Predial }\end{array}$} & D.S. $140 / 1990$ & sí & no & 140 & 8 & 132 & $1990^{(2)}$ & \\
\hline 7 & \multicolumn{2}{|l|}{$\begin{array}{l}\text { Renovación } \\
\text { Urbana }\end{array}$} & D.S. $195 / 1991$ & sí & sí & $\begin{array}{l}1000 / \\
2000\end{array}$ & $100 / 200$ & 200 & 1992 & \\
\hline 8 & \multicolumn{2}{|c|}{$\begin{array}{l}\text { Leasing } \\
\text { Habitacional }\end{array}$} & Ley 19281 & no & sí & $\begin{array}{c}1000 / \\
2000\end{array}$ & & $90 / 140$ & $120 / 60$ & $\begin{array}{c}1993 / \\
95 \\
\end{array}$ \\
\hline 9 & \multicolumn{2}{|l|}{ Chile Barrio } & D.S.33/1998 & & & & & & 1998 & \\
\hline 10 & \multicolumn{2}{|c|}{$\begin{array}{l}\text { Movilidad } \\
\text { Habitacional }\end{array}$} & D.S. $62 / 84$ & no & & & & & 1995 & \\
\hline 11 & \multicolumn{2}{|c|}{$\begin{array}{l}\text { Vivienda Social } \\
\text { Dinámica Sin Deuda }\end{array}$} & $\begin{array}{l}\text { D.S. 62/84, } \\
5 / 2002\end{array}$ & no & no & 300 & - & 280 & 2002 & \\
\hline 12 & \multicolumn{2}{|c|}{ Vivienda Nueva Básica } & $\begin{array}{l}\text { D.S. 62/84, } \\
5 / 2002\end{array}$ & no & no & 600 & - & $100 / 140$ & 2002 & \\
\hline 13 & \multicolumn{2}{|c|}{ Fondo Solidario } & D.S. $155 / 2001$ & no & no & aprox. 300 & - & 280 & 2001 & \\
\hline 14 & \multicolumn{2}{|c|}{ Subsidio Habitacional } & D.S. $40 / 2004$ & sí & sí & $600 / 1000$ & $20 / 80$ & 90 & $2004^{(3)}$ & \\
\hline
\end{tabular}

(1) Parte como Subsidio Habitacional, luego sigue como Sistema de Ahorro y Préstamo y a partir de 1988 como Subsidio General Unificado.

(2) Para construir viviendas en sitios ya ocupados; subsidio y ahorro como para la Vivienda Progresiva.

(3) Reemplaza Subsidio Unificado (SGU) y Vivienda Básica libre elección.

Fuente: MINVU (2007) . 
Especial de Trabajadores (PET), el Subsidio Rural, la modalidad Libre Elección de los programas de Vivienda Básica y Progresiva y también el actual Subsidio Habitacional D.S. 40. El segundo mecanismo de subsidio es la construcción y asignación de viviendas para grupos de bajos ingresos y con muy escasa capacidad de ahorro (la llamada vivienda económica). Dentro de este mecanismo se cuentan los programas de Vivienda Básica y Progresiva (ambas en su modalidad SERVIU, es decir donde el SERVIU construía las viviendas).

Si bien estos dos mecanismos de subsidios han sufrido constantes modificaciones en los últimos años, su estructura se ha mantenido y pueden ser considerados como los pilares de la política habitacional chilena desde 1978, obteniendo los resultados que se vieron más arriba en cuanto a aumento del stock de viviendas. En las secciones que siguen se detalla el funcionamiento de estos sistemas de subsidio habitacional. A modo de resumen y para facilitar la comprensión de los distintos programas de fomento de la vivienda, la Tabla $\mathrm{N}^{0} 5$ contiene la información básica de los principales programas habitacionales que se han usado en Chile desde 1973. Se indican las características del respectivo programa: desde cuándo existe y hasta cuándo funcionó, el monto del subsidio, si requiere ahorro previo y cuánto y si requiere de crédito hipotecario.

La Tabla $\mathrm{N}^{\circ} 6$ contiene una información que ilustra la importancia relativa de los distintos programas dentro de las políticas habitacionales. Se distinguen dos períodos: la década comprendida entre 1990 y 1999 y luego el período entre 2000 y 2007. La columna “viviendas construidas” indica la participación promedio del programa respectivo sobre el total de viviendas construidas o subsidios pagados por año durante el período. La columna "UF pagadas” indica la participación promedio del respectivo programa dentro del gasto anual del MINVU en viviendas y subsidios. Se puede apreciar en la tabla que, durante los noventa, los principales programas de subsidio a la vivienda fueron la Vivienda Básica, el Subsidio General Unificado (SGU) y el Subsidio Especial de Trabajadores (PET). En la década siguiente han cobrado importancia el Fondo Solidario para la Vivienda y el Subsidio Habitacional D.S. 40 que son parte de la Nueva Política Habitacional. 
TABLA N ${ }^{\circ}$ 6: $\quad$ IMPORTANCIA DE LOS DISTINTOS PROGRAMAS DE SUBSIDIO

\begin{tabular}{|c|c|c|c|c|}
\hline \multirow[t]{3}{*}{ Programas } & \multicolumn{2}{|c|}{ 1990-1999 } & \multicolumn{2}{|c|}{$2000-2007$} \\
\hline & \multicolumn{4}{|c|}{ Porcentaje de participación en } \\
\hline & $\begin{array}{l}\text { Viviendas } \\
\text { construidas }\end{array}$ & $\begin{array}{c}\text { UF } \\
\text { pagadas }\end{array}$ & $\begin{array}{l}\text { Viviendas } \\
\text { construidas }\end{array}$ & $\begin{array}{c}\text { UF } \\
\text { pagadas }\end{array}$ \\
\hline \multicolumn{5}{|l|}{ Vivienda } \\
\hline Vivienda Básica & 27,7 & 44,1 & 10,1 & 17,9 \\
\hline Vivienda Progresiva & 6,0 & 5,6 & 0,7 & 0,7 \\
\hline Vivienda Social Dinámica Sin Deuda & & & 3,2 & 5,0 \\
\hline \multicolumn{5}{|l|}{ Subsidio } \\
\hline General Unificado & 27,9 & 24,0 & 6,8 & 4,6 \\
\hline PET & 18,9 & 10,9 & 9,8 & 4,9 \\
\hline Rural & 8,6 & 6,7 & 8,4 & 7,4 \\
\hline Básica Privada & 3,0 & 2,9 & 5,7 & 4,2 \\
\hline Progresiva I etapa & 5,7 & 5,0 & 6,0 & 5,1 \\
\hline Progresiva II etapa & 1,7 & 0,4 & 1,0 & 0,2 \\
\hline Leasing Habitacional & 0,5 & 0,3 & 2,3 & 1,6 \\
\hline Fondo Solidario de Vivienda I (FSV I) & & & 18,0 & 29,9 \\
\hline Fondo Solidario de Vivienda II (FSV II) & & 1,2 & 1,9 & \\
\hline Subsidio a la Localización & & & 0,0 & 3,5 \\
\hline Subsidio Habitacional (DS 40) & & & 13,0 & 9,1 \\
\hline Protección Patrimonio Familiar (PPPF) & & & 4,7 & 1,0 \\
\hline \multirow[t]{2}{*}{ Mantención de Viviendas SERVIU (SMVS) } & & & 9,2 & 3,0 \\
\hline & 100,0 & 100,0 & 100,0 & 100,0 \\
\hline
\end{tabular}

Fuente: Elaboración propia en base a la información del MINVU en http://www. observatoriohabitacional.cl.

\subsection{Subsidio habitacional}

El subsidio habitacional es un mecanismo de subsidio a la demanda que está pensado para subsanar el problema de asimetría de información, reduciendo la necesidad de crédito y evitando así un excesivo riesgo para instituciones financieras que no prestarían si no hubiese un subsidio de por medio. Se trata de un voucher o certificado de subsidio para adquirir una vivienda propia, donde el beneficiario necesita financiar una parte de la vivienda con sus propios ahorros y un crédito. Este sistema de subsidio se inició bajo el nombre de "Subsidio Habitacional” en 1978 y duró hasta 1988. En 1984 se le sumó el sistema de Ahorro y Financiamiento. Ambos funcionaban bajo el principio de otorgamiento de certificados de subsidio. En 1988 estos dos sistemas se fundieron en el Subsidio General Unificado (SGU) que 
duraría hasta el año 2004. Existen también el Subsidio Rural, que funciona del mismo modo que el SGU pero está destinado a sectores rurales, y el Programa Especial de Trabajadores (PET), que beneficia a grupos de hogares y no a hogares individuales. En lo que sigue se describe con más detalle el Subsidio General Unificado que fue el de mayor impacto sobre el mercado habitacional.

El SGU permitía financiar sólo una parte del valor de la vivienda y estaba limitado a viviendas con un valor tope distribuidos en tramos. La vivienda era financiada además con ahorro de los beneficiarios, que debían certificar al postular al subsidio, y con un crédito hipotecario. En muchos casos este crédito fue otorgado por la misma autoridad (los SERVIU) debido a que, por los bajos montos involucrados, bancos privados no estaban interesados. Hasta 1995 los subsidios sólo podían utilizarse para adquirir una vivienda nueva y desde 1996 fue también posible usarlos para la adquisición de una vivienda usada.

¿Cómo funcionaba este subsidio? Los interesados postulaban al subsidio cuando cumplían con los requisitos exigidos, dentro de los cuales el más importante era alcanzar un cierto nivel de ahorro. Éste fluctuaba entre 50 y $150 \mathrm{UF}$, dependiendo del valor de la vivienda que se quería comprar. Las postulaciones se realizaban en dos o tres fechas fijas por año y, debido a que el número de postulantes superaba con creces el número de subsidios a otorgar, se les asignaba un puntaje a los postulantes que permitía seleccionar a los beneficiarios de acuerdo al nivel de ahorro (por encima del mínimo exigido), al número de personas en el hogar, al tiempo de espera, entre otros. Aquellos postulantes que no recibían el subsidio debían seguir esperando, es decir, el cumplir con los requisitos para el subsidio no garantizaba el recibirlo. Las viviendas subsidiadas alcanzaban hasta 2004 un valor máximo de 1.500 UF con un subsidio decreciente en función del valor de la vivienda. El subsidio máximo de 140 UF se entregaba para viviendas de hasta 500 UF y era decreciente para viviendas de mayor valor.

El Subsidio General Unificado entregó entre 1990 y 2007 un promedio de 23.000 certificados de subsidio anuales pero pagó en promedio 18.000. Los subsidios otorgados y pagados vienen disminuyendo paulatinamente desde 2003 debido a que el MINVU se está moviendo hacia un nuevo modelo de política habitacional. Otra modalidad del subsidio habitacional es el ya mencionado Subsidio Rural donde las viviendas subsidiadas no podían superar un valor de 400 UF. Anualmente se han otorgado en los últimos años aproximadamente 8.000 
subsidios en este programa. El Programa Especial de Trabajadores otorgaba, en cambio, el subsidio habitacional a través de postulaciones colectivas, por ejemplo, de sindicatos de trabajadores, cooperativas de vivienda u otras. A través del programa PET se otorgaban anualmente entre 10.000 y 15.000 subsidios. El Gráfico No 2 muestra la evolución del subsidio habitacional en Chile entre 1990 y 2003.

Al menos dos aspectos del funcionamiento del subsidio habitacional en Chile merecen un comentario adicional: en primer lugar, el impacto distributivo de los subsidios y, en segundo lugar, el rezago en el pago de los subsidios que parece ser excesivamente largo. Estos dos aspectos se comentan a continuación.

El subsidio habitacional no está concebido para los hogares de muy bajos ingresos de la población debido a que éstos prácticamente no tienen capacidad de ahorro y no son sujetos de crédito, sino que apunta más bien a los sectores de ingresos medios. Esto hace esperar que los beneficiarios sean principalmente del tercer quintil de ingresos. La Tabla $\mathrm{N}^{\circ} 7$ muestra el impacto distributivo que ha tenido este subsidio según la encuesta CASEN 2006 (sólo se consideran los hoga-

GRÁFICO Nº 2: $\quad$ SUBSIDIOS PAGADOS (MILES) EN EL SUBSIDIO HABITACIONAL

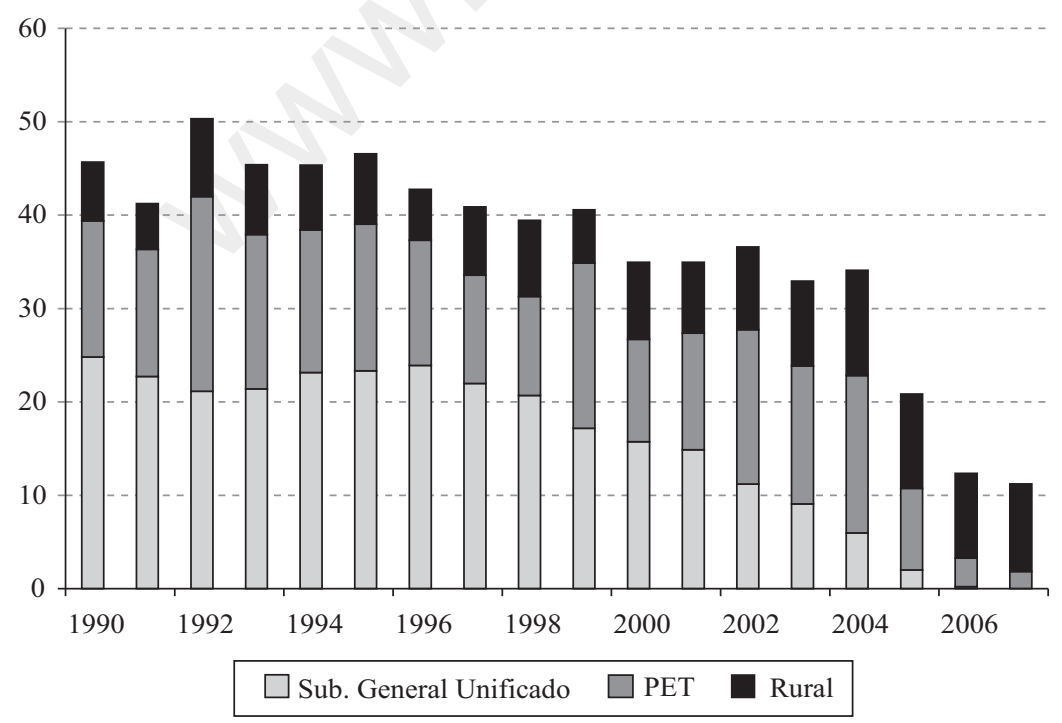

Fuente: Elaboración propia en base a la información del MINVU en http:// www.observatoriohabitacional.cl. 
TABLA N ${ }^{\circ} 7$ :

IMPACTO DISTRIBUTIVO DEL SUBSIDIO Y LEASING HABITACIONAL

\begin{tabular}{lrcrrrr}
\hline Quintil de Ingreso & I & II & III & IV & V & \\
\hline Subsidio habitacional & 7,7 & 26,2 & 20,8 & 27,7 & 17,7 & 100,0 \\
Subsidio Rural & 47,6 & 24,6 & 15,4 & 8,5 & 3,9 & 100,0 \\
P E T & 6,2 & 21,5 & 27,7 & 27,7 & 16,9 & 100,0 \\
Leasing Habitacional & 16,7 & 22,9 & 12,5 & 18,8 & 29,2 & 100,0
\end{tabular}

Fuente: Elaboración propia en base a CASEN 2006.

res que accedieron a una vivienda entre 2002 y 2006) ${ }^{28}$. Casi un $50 \%$ de los subsidios van a los dos quintiles de ingresos superiores y los quintiles dos y tres reciben el resto. El primer quintil de ingresos casi no se ve beneficiado por este subsidio ${ }^{29}$.

Varias razones explican la falta de focalización del subsidio: en primer lugar, la exigencia de un cierto nivel de ahorro y la utilización de éste para determinar el orden de prioridad de los postulantes hace que, ceteris paribus, reciban los subsidios quienes ahorran más, que son también aquellos que tienen mayores ingresos. En segundo lugar, el último tramo (en cuanto a valor de las viviendas) de subsidio era alto. Hasta hace algún tiempo se subsidiaban viviendas de hasta 1.500 UF, lo que lo hacía atractivo para hogares de ingresos más altos, aun cuando el subsidio era bajo.

El segundo aspecto que merece mención es la lentitud del subsidio habitacional en hacerse efectivo. Por cierto, la entrega de un subsidio no implica que el beneficiario adquiera inmediatamente una vivienda. Como se mencionó más arriba, en los últimos años se entregaban en promedio 23.000 subsidios pero se pagaban sólo 18.000 , con lo cual, más de un $20 \%$ de los subsidio otorgados no llevaba a la construcción o adquisición de una vivienda. El Gráfico No 3 muestra, a modo de ejemplo, los subsidios pagados del SGU a diciembre de 2003

${ }^{28} \mathrm{Al}$ mirar los hogares que accedieron antes a la vivienda no es posible medir el impacto distributivo por cuanto los hogares pueden haber cambiado de quintil de ingresos.

${ }^{29}$ Esto es un aspecto que ya ha sido tratado anteriormente en la literatura. Véase Castañeda (1990) y Castañeda y Quiroz (1986) para los primeros años de funcionamiento del subsidio y también Irarrázaval (2001), p. 141. Como señala también Simian (2004) en períodos anteriores esto no fue distinto y de los subsidios entregados entre 1994 y 1996 el 40\% se iba al cuarto y quinto quintil de ingreso. 
GRÁFICO N N $^{\circ}$ 3: $\quad$ SUBSIDIOS PAGADOS SGU SEGÚN AÑO DE OTORGAMIENTO A DICIEMBRE DE 2003 (\%)

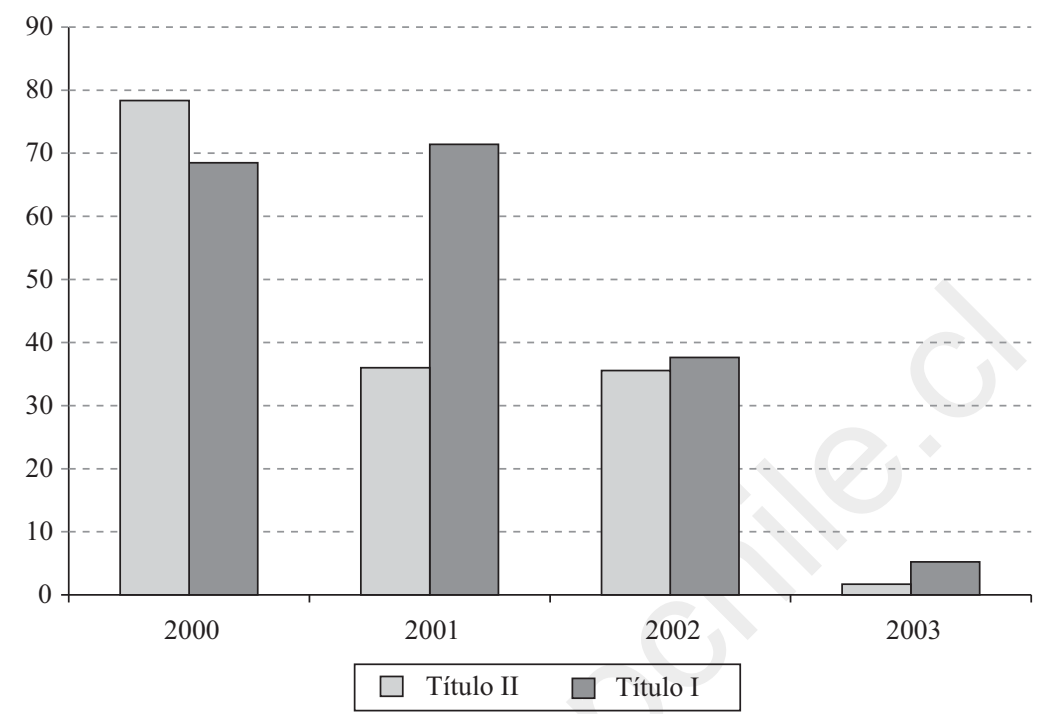

Fuente: MINVU (2006).

según fecha de otorgamiento ${ }^{30}$. Aparecen en el gráfico el Título I del subsidio, que corresponde a los certificados otorgados a postulantes individuales, y el Título II, que es la modalidad grupal, donde los subsidios son solicitados para un grupo de familias, por ejemplo, a través de proyectos de cooperativas de vivienda. Es posible ver en el gráfico que, de los subsidios otorgados ese mismo año, menos del 5\% había sido pagado hacia el final del año y de los otorgados en 2002 menos del $40 \%$. Si retrocedemos todavía más, vemos por ejemplo que de los subsidios otorgados en 2000, cuatro años antes, se había pagado menos del 70\% en 2003. Considerando que con el ahorro y el subsidio la vivienda está financiada en casi un 30\% (primer tramo para viviendas de hasta 500 UF), este resultado no deja de sorprender y cabe preguntarse por qué demora tanto el beneficiario en hacerse de una vivienda. Una de las razones para esto puede obedecer al carácter de lotería que tiene la distribución de los certificados de subsidio, unido al hecho que

${ }^{30}$ Debe considerarse que este subsidio se venía reduciendo desde el año 2000 y en 2004 se reemplazó por el Subsidio Habitacional D.S. 40. 
estos se otorgan solamente en dos o tres fechas anuales ${ }^{31}$. La adquisición de una vivienda es una decisión que involucra diversos aspectos de la vida de una familia. Por un lado se trata de una decisión a largo plazo que determinará en gran medida la calidad de vida futura. Costos de transporte, acceso a colegios y a lugares de entretención dependerán de la decisión de comprar una vivienda. Por otro lado el financiamiento de la vivienda absorberá una parte importante del ingreso del hogar durante 15 a 20 años. Si bien los costos de búsqueda de una vivienda adecuada y los de su financiamiento no son prohibitivos, tampoco pueden considerarse despreciables. Debido entonces a la incertidumbre del proceso de postulación al subsidio, es razonable suponer que los hogares interesados no iniciarán gestiones conducentes a la adquisición de una vivienda propia antes de tener certeza de haberlo obtenido ${ }^{32}$.

Otra razón para la dificultad de acceso a la vivienda podría radicar en altos costos de transacción para adquirirla en el segmento de unidades de menos de 1.000 UF. Estos costos pueden consistir en altos costos de búsqueda, costos burocráticos, demoras en trámites (incluido el obtener el pago del subsidio), etc.

Resumiendo lo anterior es posible señalar que, entre 1990 y 2007, casi un 50\% de las viviendas construidas con subsidio fueron construidas o compradas a través del subsidio habitacional (unificado, PET o rural) y recibieron casi un 35\% del monto total de los subsidios pagados por el MINVU. Por lo tanto, no cabe duda que este mecanismo de fomento de la vivienda propia ha sido un pilar fundamental de la política habitacional en Chile. Es destacable también que se trata de un sistema de subsidio a la demanda y que aprovecha el mercado habitacional. El subsidio habitacional, en la forma descrita en esta sección, se eliminó en 2004, reemplazándose por el Subsidio Habitacional D.S. 40.

\subsection{La vivienda económica}

El segundo mecanismo de subsidio de la política habitacional chilena ha sido la construcción y asignación de viviendas a través de los programas de vivienda económica. La construcción de estas vivien-

${ }^{31}$ Esto se cambió, por ejemplo, en el Leasing Habitacional, donde el subsidio se otorga cuando el solicitante cumple los requisitos para obtenerlo, no hay listas de espera ni fechas de otorgamiento. Véase la sección 4.3.

${ }^{32}$ Doña, Larrañaga y Torche (2003) sugieren la idea de moverse a "subsidios en tiempo real”, es decir que se entreguen cuando sean solicitados, en la medida que el beneficiario cumpla con los requisitos. 
das estuvo, desde mediados de los ochenta y hasta hace unos pocos años, a cargo del SERVIU y tuvo como objetivo solucionar los problemas habitacionales de los hogares de ingresos más bajos. Dentro de lo que se denomina "Vivienda Económica" ha habido diversos programas habitacionales. Los más conocidos son la Vivienda Básica, existente desde 1984, y luego, a partir de 1990, la Vivienda Progresiva.

La Vivienda Básica consistía en una vivienda de una superficie de aproximadamente $40 \mathrm{~m}^{2}$ que, inicialmente, era una casa y más tarde pasó a ser mayoritariamente un departamento dentro de edificios de hasta cuatro pisos por la escasez y alto precio del suelo, especialmente en la Región Metropolitana. La vivienda tenía hasta el año 2000 un valor que no superaba las 230 UF, de las cuales 140 UF correspondían a un subsidio, 10 UF a ahorro de los beneficiarios y el resto a un crédito que otorgaba el mismo SERVIU. Las viviendas se asignaban según un ranking de los postulantes por ingreso, ahorros, tiempo de espera, entre otros.

El Programa de Vivienda Progresiva se creó en 1990 para dar una solución rápida a los problemas habitacionales que se veían en ese momento y consistía en una caseta sanitaria con baño, cocina y una habitación ${ }^{33}$. La Vivienda Progresiva perseguía que los beneficiarios construyeran la vivienda con sus propios medios a partir de la caseta básica. La vivienda tenía $14 \mathrm{~m}^{2}$ sobre un terreno de $100 \mathrm{~m}^{2}$ y su valor ascendía a 140 UF, de las cuales 132 eran subsidio y el resto ahorro de los beneficiarios.

Entre 1990 y 2006 se terminaron en promedio 21.000 viviendas económicas por año entre viviendas básicas y progresivas (sin contar la Nueva Básica y la dos etapas adicionales de la Progresiva que añaden cerca de 12.000 viviendas más en promedio por año, especialmente a partir de 1996). Como se observa en el Gráfico No 4, la mayoría de estas viviendas han sido viviendas básicas. La Vivienda Progresiva nunca llegó a tener un peso importante dentro de la política habitacional chilena. La Vivienda Básica, en cambio, se mantuvo hasta 2002 en no menos de 20.000 unidades por año, aunque la importancia relativa de la

${ }^{33}$ En ese entonces se estimaba un déficit habitacional cuantitativo de un millón de viviendas, existiendo en ese entonces un stock de poco más de 3 millones de viviendas. Eso llevó a pensar en un programa que pudiese reducir el déficit lo más rápido posible y a bajo costo. Respecto de la situación en ese entonces, véase MacDonald (1992) y MINVU (2007), p. 232. 
GRÁFICO No 4: VIVIENDA ECONÓMICA: VIVIENDAS CONSTRUIDAS (MILES) Y SUBSIDIOS PAGADOS

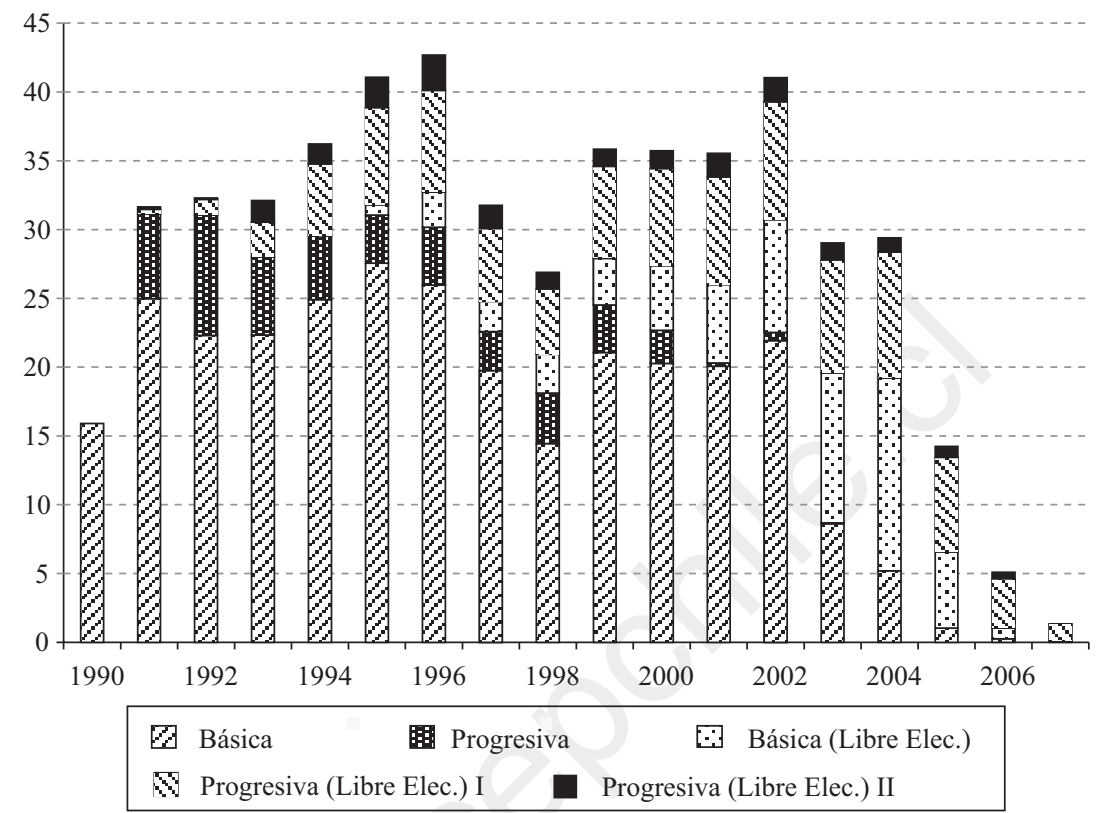

Fuente: Elaboración propia en base a la información del MINVU en http:// www.observatoriohabitacional.cl.

vivienda económica sobre el total de viviendas edificadas en Chile ha ido disminuyendo. En la vivienda económica se gastaban aproximadamente dos tercios del presupuesto del MINVU para subsidios y construcción de viviendas sociales ${ }^{34}$.

A partir de 1995 se creó la Modalidad Libre Elección tanto para la Vivienda Básica como para la Vivienda Progresiva, que consistía en entregar, en vez de una vivienda, el monto del subsidio en forma "portable" de modo que el beneficiario pudiese comprar con él una vivienda nueva o usada por un valor máximo de 230 UF. La idea detrás de esta modalidad fue aplicar la experiencia del subsidio habitacional a viviendas de menor valor. Entre 1995 y 2007 se pagaron en total poco más de 60.000 subsidios, es decir, un promedio de menos de 5.000 subsidios por año, bastante por debajo de los niveles que alcanzaba la Vivienda Básica en su modalidad SERVIU. Una de las razones para esto

${ }^{34}$ Esta información está disponible en http://www.minvu.cl. 
podría estar en un mal funcionamiento del mercado habitacional para viviendas de ese monto y subsidios ocultos de la Modalidad SERVIU de la Vivienda Básica. El problema de este mercado y la falta de movilidad habitacional se discutirá más abajo ${ }^{35}$.

La Tabla $\mathrm{N}^{\circ} 8$ muestra el impacto distributivo de los programas de vivienda económica de acuerdo a la encuesta CASEN 2006. La Vivienda Básica se concentra en más de un $50 \%$ en los dos primeros quintiles de ingreso entre 2002 y 2006. Se trata por tanto de un instrumento que está mejor focalizado hacia los segmentos de menores ingresos. Con este tipo de programas ha sido posible asignar una vivienda propia a hogares de muy bajos ingresos, lo que hace que en Chile la vivienda propia esté distribuida de manera similar en todos los quintiles de ingreso.

Se señalan a continuación brevemente tres problemas asociados a la vivienda económica en Chile: su supuesta falta de calidad, el hacinamiento en ellas y el problema de los deudores habitacionales. Existe también un problema de segregación de los hogares beneficiarios de estas viviendas que se discutirá más abajo ${ }^{36}$.

Si bien la vivienda económica ha permitido solucionar los problemas habitacionales de los hogares con menores ingresos, ha habido problemas de calidad de las viviendas que salieron a la luz pública especialmente luego de los daños producidos en algunas viviendas de este tipo por efectos de unas fuertes lluvias en junio de 1997. ¿Dónde está el problema?

La construcción de viviendas económicas se realizaba a través de proyectos del SERVIU que licitaba a empresas constructoras regis-

IMPACTO DISTRIBUTIVO DE LA VIVIENDA ECONÓMICA

\begin{tabular}{|c|c|c|c|c|c|c|}
\hline Programa/quintil de ingreso & I & II & III & IV & V & \\
\hline Vivienda Básica & 33,1 & 20,4 & 23,2 & 15,5 & 7,7 & 100,0 \\
\hline Vivienda Progresiva & 26,8 & 30,4 & 26,8 & 10,7 & 5,4 & 100,0 \\
\hline Subsidio Vivienda Básica & 26,5 & 33,6 & 21,2 & 11,5 & 7,1 & 100,0 \\
\hline Subsidio Vivienda Progresiva & 40,6 & 21,0 & 20,3 & 13,3 & 4,9 & 100,0 \\
\hline
\end{tabular}

Fuente: Elaboración propia en base a CASEN 2006.

\footnotetext{
${ }^{35}$ Véase sección 6.2.

${ }^{36}$ Véase sección 6.1.
} 
tradas la edificación de las viviendas. Hasta 1983 se fijaba el número de viviendas a construir y el monto a gastar y se entregaba la construcción a la empresa que ofreciera los mejores estándares de calidad para las viviendas. A partir de ese año se fijaron unos estándares mínimos de calidad y se entregó la construcción a la empresa que ofrecía construir el mayor número de viviendas, lo que ha ido en desmedro de su calidad ${ }^{37}$. Sin embargo, como se mostrará más adelante ${ }^{38}$, la vivienda económica no es la de peor calidad y, aun cuando ella muestra en zonas urbanas índices de conservación de materiales y de materialidad inferiores a las viviendas del subsidio habitacional, estos índices son mejores que los de las viviendas sin subsidio ocupados por hogares en el mismo quintil de ingreso.

Otro de los problemas de la vivienda económica ha sido el hacinamiento de los hogares beneficiados. En efecto, las comunas donde se localizan muchas viviendas económicas muestran una alta densidad. Galetovic y Poduje (2006) señalan para el caso de Santiago que, si bien la densidad ajustada (población total de la comuna dividida por su área urbanizada) ha disminuido desde 96,5 hab./ha en 1992 a 85,1 hab./ha en 2002, es más alta en las comunas donde se han construido las viviendas sociales, como son Puente Alto (125 hab./ha), Cerro Navia (164 hab./ha) o La Pintana (114 hab./ha), entre otras.

Un tercer problema ligado a este programa de vivienda es el de los deudores habitacionales. La necesidad de financiar la Vivienda Básica en parte con un crédito hipotecario y la falta de oferta privada de créditos de menos de 300 UF para financiar viviendas, hizo que éstos fueran otorgados en el pasado por los propios SERVIU. La cartera de créditos de estas instituciones mostró rápidamente altos niveles de morosidad y continuas protestas públicas de los deudores habitacionales que reclamaban la condonación parcial o total de sus deudas ${ }^{39}$. Actualmente esto ha dejado de ser un problema y de acuerdo a la encuesta CASEN 2006, el 0,8\% de quienes han recibido un crédito SERVIU estaba moroso en los pagos a esa fecha. Esta cifra llegaba a casi 2,5\% en 2003 de acuerdo con la misma encuesta para ese año. En

${ }^{37}$ Véase CEPAL (1996), p. 178.

${ }^{38}$ Véase sección 6.3 y especialmente la Tabla No 12.

${ }^{39}$ No hay muchos trabajos respecto de la evolución de la cartera morosa de deudores habitacionales. Para la situación a mediados de los noventa, véase el trabajo de Melo (1995). Allí se muestra que en promedio se devolvía el 65\% del crédito otorgado y que casi un $80 \%$ de los créditos se volvía moroso. Aquí debe verse un subsidio oculto adicional a la vivienda económica en Chile. 
su nueva política habitacional a partir de los años 2000, el MINVU decidió moverse hacia viviendas que se financian solamente con el ahorro y el subsidio y no contemplan ningún tipo de crédito.

La vivienda económica ha hecho un aporte muy significativo para dar solución a las necesidades habitacionales de muchas familias en el país. Sin embargo, la masiva aplicación de estos programas ha venido generando los problemas mencionados más arriba. Estos problemas han llevado al desarrollo de la Nueva Política Habitacional, que se aborda luego de describir el programa de Leasing Habitacional.

\subsection{El Leasing Habitacional}

Una característica común a todos los programas para acceder a la vivienda propia en Chile es la exigencia de algún tipo de ahorro. Sin embargo, hay hogares con muy baja capacidad de ahorro que tardarían mucho tiempo en poder reunir suficientes recursos para acceder a los subsidios tradicionales para la vivienda, lo que se puede dar especialmente en hogares que pagan arriendos muy altos. Con el objeto de facilitar a este tipo de hogares el acceso a la vivienda propia se creó en 1996 un nuevo programa de subsidio para la vivienda, el llamado Leasing Habitacional.

El Leasing Habitacional es un sistema en que el tomador del leasing arrienda la vivienda al mismo tiempo que ahorra para su compra. Funciona de la siguiente manera: el interesado en adquirir una vivienda debe por un lado cerrar un contrato con una sociedad inmobiliaria que tenga giro exclusivo de leasing habitacional y que le arrendará la vivienda con la obligación de comprarla al término de la duración del contrato. Previo al contrato con la sociedad inmobiliaria debe cerrar un contrato de ahorro con una Administradora de Fondos para la Vivienda (AFV) con el objeto de acumular la cantidad necesaria para comprar la vivienda. El tomador del leasing paga una sola cuota que va en parte a la AFV como ahorro y en parte a la sociedad inmobiliaria como arriendo. Si la vivienda cumple con una serie de condiciones el tomador del leasing puede solicitar un subsidio que se le otorga en cuotas durante la duración del contrato. El leasing habitacional no exige ningún tipo de ahorro previo. Los hogares deben simplemente postular y se les otorga el subsidio en la medida que cumplan con los requisitos. No hay lista de espera ni ranking de postulantes como en los demás 
programas. Esto es inédito dentro del sistema de subsidio habitacional chileno. El subsidio que se entrega asciende a 140 UF y permite financiar viviendas de hasta 1.000 UF (y de hasta 2.000 UF en zonas de interés territorial o de rehabilitación histórica).

En comparación con el subsidio tradicional, el leasing resulta siempre una alternativa más cara porque, en el financiamiento tradicional, el pago de intereses va disminuyendo en la medida que se va devolviendo el crédito. Sin embargo, el leasing aparece como la única opción para aquellos hogares que no logran reunir suficientes ahorros ${ }^{40}$.

Si bien el Leasing Habitacional pareció inicialmente un programa promisorio, no ha alcanzado gran peso dentro de los programas del MINVU. Actualmente se financian a través de este sistema alrededor de 4.000 viviendas por año y los subsidios asociados son alrededor de un $4 \%$ de los recursos que el MINVU gasta anualmente en subsidios. Como puede apreciarse en la Tabla $\mathrm{N}^{\circ} 7$ el Leasing Habitacional es utilizado principalmente por hogares de los dos quintiles superiores de ingreso.

\section{Nueva política habitacional}

A partir del año 2000 la política habitacional chilena ha sufrido una serie de cambios como son la eliminación de algunos programas habitacionales, la modificación de otros y la aparición de nuevos programas de subsidio a la vivienda. Estos cambios permiten afirmar que la política habitacional ha virado de rumbo ${ }^{41}$. Los principales cambios que se han producido son tres: en primer lugar se ha reducido el monto del subsidio habitacional (de los voucher) y se ha reducido también el valor máximo de las viviendas a subsidiar. Este cambio pareciera buscar una mejor focalización del subsidio habitacional y subsana así el problema descrito más arriba. En segundo lugar el MINVU (a través de los SERVIU) ha abandonado su papel constructor. Como se mencionó más arriba, la Vivienda Básica y también la Vivienda Progresiva, ambas en su modalidad SERVIU, fueron subsidios que se aplicaron sobre un stock nuevo de viviendas, construido por los propios SERVIU, que actuaban como grandes empresas inmobiliarias. A raíz de los proble-

\footnotetext{
${ }^{40}$ Véase sobre esto el análisis de Eschenburg y Simian (1999).

${ }^{41}$ Ravinet (2004) explica el porqué de estos cambios desde la perspectiva del MINVU.
} 
mas de falta de calidad de las viviendas y segregación de las familias más pobres en la periferia urbana, la política se ha movido a un desarrollo de proyectos habitacionales público-privado que intente conseguir mejores localizaciones y mejor calidad de las viviendas. Para esto el subsidio es más alto y se utilizan entidades privadas que "organicen la demanda”, es decir, que reúnan a las familias interesadas, desarrollen un proyecto inmobiliario para ellas y postulen con el proyecto completo al subsidio. Un tercer elemento de cambio es la supresión de los créditos SERVIU para la compra de viviendas por parte de familias de bajos ingresos.

Dentro de esta nueva política habitacional y con los cambios mencionados, existen varios nuevos programas de subsidio a la vivienda. Los más importantes son el Subsidio Habitacional D.S. 40 y el Fondo Solidario de Vivienda que se discuten a continuación. Al final del capítulo se mencionan algunos otros de menor importancia.

\subsection{Subsidio Habitacional D.S. 40}

El Subsidio General Unificado y la Modalidad Libre Elección de la Vivienda Básica confluyeron en un único programa llamado "Subsidio Habitacional” que se creó en 2004 a través del Decreto Supremo Nr. 40. Este programa opera de la misma manera que el SGU descrito más arriba. La diferencia fundamental es que tiene sólo dos tramos de subsidio en vez de tres con un límite superior menor (viviendas hasta 600 UF en el primer tramo y de hasta 1.000 UF en el segundo tramo). Además, el monto del subsidio se redujo de manera importante, quedando en 90 UF. Desde 2004 se han entregado más de 50.000 subsidios de este tipo. En los últimos dos años, el número de subsidios pagados supera los 20.000 por año.

\subsection{Fondo Solidario de Vivienda}

Se trata de un programa de subsidio que financia la construcción de viviendas nuevas o la compra de viviendas usadas por un valor de hasta $470 \mathrm{UF}$, dependiendo de la comuna donde se ubique la vivienda, ya que se subsidian valores mayores en comunas más extremas del país. Se trata de un subsidio dirigido a hogares en situación de pobreza, 
medida a través de la Ficha de Protección Social (ex ficha CAS), se exige un ahorro mínimo de 10 UF y no requiere ningún tipo de crédito adicional. Las viviendas son construidas por una Entidad de Gestión Inmobiliaria (EGIS), en la que el beneficiario debe estar inscrito. Las EGIS pueden ser instituciones públicas o privadas con o sin fines de lucro. En el caso de las entidades públicas se trata, por ejemplo, de municipalidades o corporaciones municipales y en el caso de las privadas se trata, por ejemplo, de sociedades inmobiliarias, cooperativas de vivienda, fundaciones o corporaciones de vivienda.

Los proyectos que son realizados por las EGIS deben contemplar una serie de elementos de equipamiento urbano como son áreas verdes, plazas, etc., y son aprobados en su conjunto. Cada proyecto debe involucrar al menos a 10 hogares. Los subsidios se otorgan según un puntaje que se asigna a cada proyecto y este puntaje considera los niveles de vulnerabilidad y situación de pobreza de las familias beneficiarias.

A diciembre de 2008 el MINVU registra 233 proyectos aprobados de distintas EGIS en ese año. La mediana de familias beneficiadas por proyecto fue de 44 (el promedio fue de 64 familias). En total esto implicaba la construcción de viviendas para 15.000 familias en todo el país. Entre 2002 y 2007 se han pagado casi 120.000 subsidios y más del 50\% de los recursos del MINVU se canaliza a través de este programa. El subsidio ha promediado aproximadamente 300 UF por vivienda y, en su gran mayoría, se ha aplicado a la construcción de viviendas nuevas. En efecto, según información del MINVU entre 2006 y 2008 se otorgaron poco menos de 7.000 subsidios para "Adquisición de Viviendas Construidas”, mientras que en ese mismo período se otorgaron en total de 95.000 subsidios a través del Fondo Solidario.

$¿$ ¿Soluciona este programa de subsidio los problemas que presentaban los anteriores programas de subsidio habitacional? Es muy pronto para poder emitir un juicio claro al respecto pero hay algunos indicios. Dada la limitación en el valor de la vivienda en menos de 400 UF en la mayoría de las regiones del país, el subsidio resulta bien focalizado y de acuerdo a la encuesta CASEN 2006 casi el 70\% de los subsidios se pagaba a los dos primeros quintiles de ingreso (véase Tabla $\mathrm{N}^{\circ}$ 9). En cuanto a la calidad de las viviendas es posible señalar que, de acuerdo a los índices de materialidad para pisos, muros y techo de la encuesta CASEN 2006, en promedio, el 78\% de las viviendas tiene un índice 


\begin{tabular}{lrrrrrr}
\hline Programa/quintil de ingreso & I & II & III & IV & V & \\
\hline Fondo Solidario de Vivienda & 38,3 & 28,4 & 14,8 & 16,0 & 2,5 & 100,0 \\
Vivienda Social Dinámica & 42,4 & 29,3 & 15,8 & 9,6 & 2,9 & 100,0 \\
Subsidio de Renovación Urbana & 7,4 & 7,4 & 18,5 & 40,7 & 25,9 & 100,0 \\
\hline
\end{tabular}

Fuente: Elaboración propia en base a CASEN 2006.

"bueno” y otro 16\% “aceptable”. Estas cifras son las más altas dentro de las viviendas construidas con programas habitacionales de viviendas económica (básica, progresiva, etc.). Sin embargo, debe tenerse en consideración que las viviendas son más recientes y es lógico esperar que todavía estén en buen estado.

\subsection{Otros programas habitacionales}

Con el objeto de completar la descripción de los programas de la política habitacional en Chile se agregan en lo que sigue algunos más que no han sido mencionados anteriormente.

Vivienda Social Dinámica sin Deuda: Este programa busca proveer de vivienda a los segmentos más pobres de la población. El subsidio cubre la construcción de una pequeña vivienda de hasta $25 \mathrm{~m}^{2}$ y que puede ser ampliada por el usuario más tarde. Se exige un ahorro mínimo de 10 UF y el valor del subsidio es de 280 UF. Desde 2003 se han construido cerca de 17.000 viviendas con este programa. Actualmente está perdiendo importancia dentro de la paleta de programas de subsidio habitacional que promueve el MINVU (véase el Gráfico N 5).

Movilidad Habitacional: Ya hacia mediados de los noventa se empezó a hacer patente que los sistemas de subsidio enfocados hacia la construcción de viviendas nuevas tenían un impacto negativo en el valor de las viviendas sociales ya existentes que no pueden ser adquiridas si no es con un fuerte castigo en el precio ${ }^{42}$. Esto llevó a que el MINVU fuese extendiendo paulatinamente el pago de subsidios (tanto del SGU como de la Vivienda Básica de Libre Elección) a viviendas usadas con el objetivo de permitir un mayor desarrollo del mercado de

\footnotetext{
${ }^{42} \mathrm{~A}$ menos que eso haya sido compensado por un alza en el precio del suelo.
} 
GRÁFICO N N $^{\circ}$ : NUEVA POLÍTICA HABITACIONAL : SUBSIDIOS PAGADOS Y VIVIENDAS TERMINADAS (MILES)

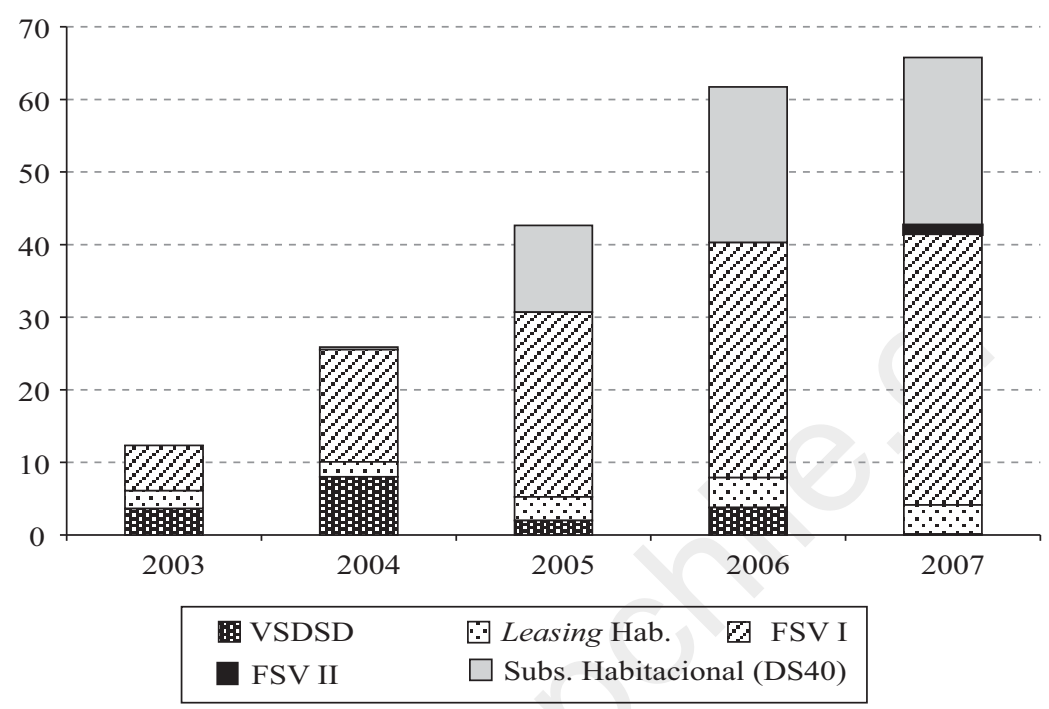

Fuente: Elaboración propia en base a la información del MINVU en http:// www.observatoriohabitacional.cl.

viviendas de bajo precio ${ }^{43}$. Sin embargo, las viviendas que han recibido un subsidio están sujetas a una prohibición de enajenación durante cinco años o mientras esté pendiente el pago de alguna deuda con el SERVIU. Para levantar esta prohibición se creó en 1995 el programa "Movilidad Habitacional" que permite a propietarios de una vivienda social, sujeta a la prohibición de enajenación o bien para la cual el propietario todavía sea deudor del SERVIU, adquirir otra. Esto no implica ningún nuevo subsidio. De acuerdo al propio MINVU el arranque ha sido lento ${ }^{44}$. No existe información respecto de cuántas operaciones de este tipo se realizan al año.

Programa de Renovación Urbana y Desarrollo Prioritario: En 1991 se creó este programa destinado a fomentar la construcción de viviendas en zonas que han sido declaradas de renovación urbana. Se trata de zonas en los centros urbanos que han ido quedando abandona6.2.

${ }^{43}$ Los problemas de la movilidad habitacional se abordan más abajo. Véase sección

${ }^{44}$ Véase MINVU (2007), p. 307. 
das, o corren el riesgo de serlo, y que a veces presentan un fuerte deterioro del stock habitacional. El subsidio es de 200 UF y permite financiar la construcción de viviendas de hasta 2.000 UF. Se trata por tanto de un subsidio dirigido más bien a segmentos medios y altos y que tiene una finalidad de desarrollo urbano más que social. En efecto, es un subsidio que ha beneficiado en más de un $60 \%$ a los quintiles de ingreso IV y V, de acuerdo a la encuesta CASEN 2006 según puede apreciarse en la Tabla $\mathrm{N}^{\circ} 9^{45}$.

Programa Chile Barrio: En 1996 se levantó un catastro de los asentamientos irregulares en Chile, es decir, de aquellas poblaciones de más de 20 viviendas instaladas en terrenos de terceros y con carencia de servicios básicos como agua, electricidad y acceso a la red de alcantarillado ${ }^{46}$. En ese entonces se contabilizaron 972 asentamientos irregulares que albergaban a casi 94.000 hogares. El programa Chile Barrio está dirigido a mejorar la situación de esos asentamientos en todos los ámbitos de pobreza como son la inserción social y laboral y también el mejoramiento de la vivienda.

Cabe preguntarse ahora si los programas de la Nueva Política Habitacional anteriormente descritos serán capaces de responder a las actuales necesidades del mercado habitacional chileno y de subsanar los problemas de los programas mencionados en cuanto a focalización por un lado y a segregación, calidad y movilidad habitacional, por otro. La siguiente sección aborda esta pregunta.

\section{Desafíos para la política habitacional}

Después de varias décadas de aplicación de masivos programas de subsidio habitacional hay resultados claramente visibles: por un lado, el déficit habitacional se ha reducido de manera importante y, si bien todavía lo hay, no es tan cuantioso y permite aplicar políticas más puntuales para superarlo. La gran mayoría de las viviendas en el país cuenta con estándares mínimos en cuanto a acceso a agua potable, alcantarillado y electricidad. Como se mostró más arriba, también se ha

\footnotetext{
${ }^{45}$ De acuerdo a la información del MINVU, en 2008 un 11\% de los subsidios del Subsidio Habitacional D.S. 40 fueron de Renovación Urbana. En 2007 fueron un 6\%.

46 También se consideraron como asentamientos irregulares agrupaciones de sesenta y más viviendas en ciudades con más de 100.000 habitantes y que carecen de servicios básicos.
} 
podido ir mejorando la materialidad de las viviendas y el número de viviendas permanentes se ha incrementado de modo notorio. Además, los hogares cuentan no sólo con vivienda sino que en casi un $80 \%$ son propietarios de las viviendas que ocupan.

Al mismo tiempo se han vuelto cada vez más visibles ciertos efectos secundarios y negativos de la política habitacional de las últimas décadas como son (1) la segregación de los hogares más pobres en la periferia urbana, especialmente en la Región Metropolitana; (2) la menor movilidad de los hogares de menores ingresos y que habitan viviendas de subsidio y (3) la presunta mala calidad de las viviendas sociales.

\subsection{Segregación}

Uno de los principales problemas de la aplicación masiva de subsidios para la vivienda económica ha sido la segregación de los hogares beneficiados, los cuales han sido radicados en los extremos de los centros urbanos, especialmente en el caso de las viviendas construidas en la Región Metropolitana. Como muestra Petermann (2006), la expansión de Santiago en los últimos 30 años ha sido llevada a cabo en buena medida por el propio MINVU y su política de construcción de viviendas sociales ${ }^{47}$. Se ha privilegiado la construcción de grandes cantidades de viviendas en la periferia de las ciudades, lo que ha permitido expandir el stock de viviendas rápidamente y a bajo costo, pero se han creado grandes bolsones de hogares de menores ingresos en los extremos de la ciudad. Esta situación disminuye la calidad de vida y el bienestar de los hogares beneficiados por estas políticas ya que deben vivir alejados de los lugares de trabajo y educación. Esta segregación conlleva, además, el peligro de que se produzcan brotes de pobreza y delincuencia en las poblaciones en cuestión que son difíciles de erradicar.

Se trata de un problema que ya ha sido mencionado hace algún tiempo ${ }^{48}$. Más recientemente, Tokman (2006) señala que la política habitacional en el Gran Santiago ha tenido un sesgo perificador, es decir, ha llevado a las familias de menores ingresos a los extremos de

${ }^{47}$ También lo ve así Hidalgo (2007), cuyo trabajo contiene a su vez una perspectiva histórica de este problema.

${ }^{48}$ Véase Simian (2000), p. 179. 
Santiago. Ella muestra que, cuando los hogares pueden elegir, como es el caso del subsidio habitacional o la Modalidad Libre Elección de la Vivienda Básica o Progresiva, eligen mayor cercanía al centro de la ciudad.

¿Solucionan este problema los programas de la Nueva Política Habitacional? Con el nuevo Subsidio Habitacional, al igual que anteriormente con el Subsidio General Unificado, no debieran presentarse problemas de segregación de los hogares beneficiados ya que los subsidios permiten que los hogares compren o construyan una vivienda en el lugar que ellos quieran. Los problemas pueden presentarse más bien por la falta de un mercado habitacional suficientemente desarrollado para las viviendas bajo las 1.000 UF. Este problema se abordará en la sección siguiente.

En el caso del Fondo Solidario para la Vivienda (FSV) podrían presentarse problemas de segregación. Una clara ventaja de este programa versus las modalidades SERVIU de los programas de Vivienda Básica y Progresiva es que ya no es el SERVIU quien construye. Los proyectos son llevados a cabo por las EGIS. En la medida que éstas actúen como sociedades inmobiliarias privadas, es posible que haya un mayor incentivo para desarrollar proyectos que consideren una mejor combinación entre atributos de las viviendas y localización. Sin embargo, las viviendas a subsidiar no pueden superar las 400 UF, lo cual hace casi imposible encontrar localizaciones muy céntricas y, en efecto, de acuerdo a la información del MINVU, entre 2006 y 2008 se otorgaron aproximadamente 10.000 subsidios a través del FSV en la Región Metropolitana. El 40\% de éstos están en tres comunas: Puente Alto, La Pintana y San Bernardo, que son las mismas donde entre 1990 y 1998 se construyó casi el 60\% de las viviendas SERVIU ${ }^{49}$. Pareciera por tanto que el FSV tendrá el mismo efecto segregador que tuvieron antes los programas de vivienda económica.

\subsection{Movilidad y mercado habitacional}

Con el tiempo y a través de su ciclo de vida los hogares pueden cambiar de tamaño y puede cambiar también su ingreso, lo que lleva a que busquen ajustar su vivienda a sus nuevas circunstancias. Para este

${ }^{49}$ Véase Doña, Larrañaga y Torche (2003), p. 7. Por otra parte esto resulta casi inevitable dado el bajo monto del subsidio (hasta 300 UF) y los actuales precios de suelos. 
ajuste la movilidad es necesaria. Lo es también desde el punto de vista de mejorar la empleabilidad y la calidad de vida de aquellos hogares que viven muy alejados de los lugares donde trabajan, se educan, etc. El problema de la movilidad habitacional consiste en la dificultad de los hogares de menores ingresos para vender su vivienda y comprar otra, o bien, arrendar la que tienen a un tercero y arrendar o comprar para sí otra. Éste es un problema que el propio MINVU detectó hace tiempo y le llevó a desarrollar el programa de Movilidad Habitacional en 1995 que, al parecer, no ha sido muy exitoso ${ }^{50}$. Desde el punto de vista del mercado habitacional también es relevante la movilidad ya que permite asignar mejor las viviendas existentes a las necesidades de los hogares y aprovechar así el stock habitacional disponible.

Herrera (2007) y antes Herrera y Valenzuela (2003) muestran que ha habido un asentamiento (los autores lo han llamado así) de la población en Chile entre los dos últimos censos de población y vivienda, en 1992 y en 2002, reduciéndose la movilidad habitacional entre esos años. Herrera (2007) mide la movilidad usando los censos de población de 1992 y 2002 y utiliza como variable de movilidad habitacional el cambio de comuna. De 18,7\% en 1992 a 16\% en 2002 disminuye el número de hogares que cambia de comuna. Además, en comparación con otros países la movilidad en Chile es baja. En los Estados Unidos casi un 15\% de la población cambió de residencia entre 2000 y 2001, es decir, cambió en un año casi tanto como los chilenos en diez años ${ }^{51}$.

Con los datos de la encuesta CASEN 2006 puede mostrarse que este asentamiento se ha mantenido, ya que se incluyó en ella una pregunta respecto del cambio de comuna de los hogares encuestados entre abril de 2002 (fecha del Censo 2002) y 2006 en que se tomó la encuesta. Y podemos utilizar el cambio de comuna como proxie de movilidad, es decir, como una variable aproximada para medir la movilidad habitacional. Debe hacerse la salvedad de considerar que puede haber cambios de vivienda dentro de una misma comuna que no serán registrados. La información podría, por lo tanto, subestimar el número de hogares que cambiaron su vivienda.

Una primera mirada sobre la movilidad contiene la Tabla $\mathrm{N}^{\circ} 10$, donde aparecen los cambios de comuna según quintil de ingreso para

${ }^{50}$ Respecto del funcionamiento de este programa véase sección 5.3. El propio MINVU no dispone de información respecto del número de operaciones realizadas por año.

${ }^{51}$ Véase Herrera (2007) y Herrera y Valenzuela (2003). 
TABLA No 10: $\quad$ MOVILIDAD HABITACIONAL SEGÚN QUINTIL DE INGRESO (ZONAS URBANAS)

¿En qué comuna o lugar vivía Ud. en abril de 2002? (\%)

\begin{tabular}{lrrrrrr} 
& I & II & III & IV & V & Todos \\
\hline En esta comuna & 94,7 & 94,1 & 93,7 & 91,5 & 86,6 & 92,5 \\
En otra comuna & 5,3 & 5,9 & 6,3 & 8,5 & 13,4 & 7,5 \\
\cline { 2 - 7 } & 100,0 & 100,0 & 100,0 & 100,0 & 100,0 & 100,0 \\
\hline
\end{tabular}

Fuente: Elaboración propia en base a CASEN 2006.

las zonas urbanas del país. Se han excluido las zonas rurales donde la movilidad es menor y obedece a patrones distintos de los urbanos. Del total de hogares encuestados en zonas urbanas en la CASEN 2006 (algo menos de 45.000), sólo un 7,5\% se movió de comuna entre 2002 y 2006. Ésta es una cifra que parece relativamente baja pero acorde al hecho que la gran mayoría de los hogares son propietarios y los propietarios se mueven menos. De acuerdo a la encuesta, el 50\% de los hogares que se cambiaron de comuna son arrendatarios. Por otra parte, si miramos los quintiles de ingreso, como puede apreciarse en la Tabla 10, del total de hogares encuestados, en el primer quintil sólo un 5,3\% cambió su comuna de residencia versus casi un 13,4\% de los encuestados del quinto quintil. Pareciera por tanto haber también una relación entre ingresos y movilidad, en la cual a mayor ingreso mayor movilidad. Esto coincide con la evidencia encontrada por Herrera (2007) quien compara la movilidad en base a los censos 1992 y 2002 y muestra que los hogares pobres se mueven menos ${ }^{52}$.

Para ver cuáles son los factores más relevantes que determinan la movilidad y estimar si la política habitacional tiene algún efecto sobre ella, se estimó una regresión logística (un logit) sobre la decisión de cambio de comuna entre 2002 y 2006, utilizando los datos de la encuesta CASEN. Con esta regresión se intenta medir el efecto de diferentes variables sobre la probabilidad de cambio de comuna, considerando que esta variable es nuestro proxie de movilidad habitacional. Como variables explicativas se usaron el ser arrendatario, el tener una vivienda cedida por servicios y cedida por familiares, el haber recibido un subsi-

52 Véase Herrera (2007), p. 73. 
dio habitacional (D.S. 40, Unificado o PET), el haber recibido una vivienda económica (Vivienda Básica o Progresiva), la edad del jefe del hogar y el quintil de ingreso autónomo. En alguna de las estimaciones se incluyeron también la escolaridad del jefe del hogar, que a su vez parece tener un efecto sobre la movilidad ${ }^{53}$. Para estos efectos se construyó una variable de escolaridad que toma el valor 1 si la escolaridad es mayor a 12 años y 0 en caso contrario. Todas las variables explicativas son dicotómicas (sí o no, y toman el valor 0 ó 1). Las variables dicotómicas que miden la tenencia de vivienda (arrendar, cedida por servicios, por familia, subsidio habitacional o vivienda económica) son excluyentes entre sí, también los grupos de edades y los quintiles de ingreso.

Los resultados aparecen en la Tabla $\mathrm{N}^{\circ} 11$. El modelo se estimó en tres especificaciones distintas según aparece en la tabla. En la estimación se considera un caso base que es un hogar propietario de la vivienda, no receptor de subsidio habitacional, cuyo jefe de hogar es menor de 25 años, pertenece al primer quintil de ingreso y tiene una escolaridad menor a 12 años. Las variables que se utilizan, y cuyo impacto sobre la probabilidad de cambio de comuna interesa medir, indican cuánto cambia la probabilidad de que el hogar se mueva si salimos del caso base, es decir, si el hogar pasa de ser propietario a ser arrendatario, o aumenta la edad o su quintil de ingresos, etc. Esta información está contenida en la columna "Efecto", que mide el efecto marginal en puntos porcentuales de un cambio en la variable explicativa (de 0 a 1).

El ocupar una vivienda "Cedida por servicios" tiene el mayor impacto sobre esa probabilidad, aumentándola aproximadamente 30 puntos porcentuales. En orden de importancia le sigue el ser arrendatario que aumenta la probabilidad en aproximadamente 25 puntos porcentuales, dependiendo de la especificación. Esto parece esperable. Sin embargo, el ser propietario de una vivienda económica (básica, progresiva, etc.) disminuye la probabilidad de cambio entre 2,5 y casi 3 puntos porcentuales. El subsidio habitacional también tiene un efecto negativo, cuantitativamente algo menor, pero que no es significativo. Este efecto, al menos en el caso de la vivienda económica, es relevante ya que los hogares que han sido beneficiarios de la vivienda económica son propietarios y la probabilidad de moverse ya es bastante baja (el

${ }^{53}$ Véase Herrera (2007), p. 70. 
TABLA N ${ }^{\circ} 11: \quad$ ESTIMACIÓN DE MOVILIDAD HABITACIONAL (LOGIT)

Variable dependiente: Cambio de Comuna entre 2002 y 2006

Especificación

1

3

Coef. Efecto Coef. Efecto Coef. Efecto

\begin{tabular}{|c|c|c|c|c|c|c|}
\hline Constante & $\begin{array}{r}-2,416 * * \\
(0,103)\end{array}$ & & $\begin{array}{r}-2,303 * * \\
(0,096)\end{array}$ & & $\begin{array}{r}-1,785 \\
(0,222)\end{array}$ & \\
\hline Arrendador & $\begin{array}{r}1,669 * * \\
(0,048)\end{array}$ & 24,0 & $\begin{array}{r}1,685^{* *} \\
(0,048)\end{array}$ & 25,9 & & \\
\hline "Cedida por servicios" & $\begin{array}{r}1,889 * * \\
(0,087)\end{array}$ & 28,9 & $\begin{array}{r}1,909 * * \\
(0,087)\end{array}$ & 31,2 & & \\
\hline “Cedida familiar” & $\begin{array}{r}0,505^{* *} \\
(0,065)\end{array}$ & 4,7 & $\begin{array}{r}0,459 * * \\
(0,065)\end{array}$ & 4,6 & & \\
\hline Subsidio Habitacional & $\begin{array}{r}-0,145 \\
(0,125)\end{array}$ & $-1,0$ & $\begin{array}{r}-0,146 \\
(0,125)\end{array}$ & $-1,1$ & $\begin{array}{r}-0,170 \\
(0,126)\end{array}$ & $-2,0$ \\
\hline Vivienda Económica & $\begin{array}{r}-0,372 * * \\
(0,110)\end{array}$ & $-2,4$ & $\begin{array}{r}-0,420 * * \\
(0,109)\end{array}$ & $-2,9$ & $\begin{array}{r}-0,389 * * \\
(0,111)\end{array}$ & $-4,2$ \\
\hline Edad entre 25 y 35 & $\begin{array}{r}-0,406 * * \\
(0,092)\end{array}$ & $-2,6$ & $\begin{array}{r}-0,384 * * \\
(0,092)\end{array}$ & $-2,7$ & $\begin{array}{r}-0,828 * * \\
(0,223)\end{array}$ & $-7,5$ \\
\hline Edad entre 36 y 45 & $\begin{array}{r}-0,957 * * \\
(0,094)\end{array}$ & $-4,9$ & $\begin{array}{r}-0,945^{* *} \\
(0,094)\end{array}$ & $-5,3$ & $\begin{array}{r}-1,636^{* *} \\
(0,221)\end{array}$ & $-11,2$ \\
\hline Edad sobre 45 & $\begin{array}{r}-1,452 * * \\
(0,094)\end{array}$ & $-6,1$ & $\begin{array}{r}-1,393 * * \\
(0,094)\end{array}$ & $-6,7$ & $\begin{array}{r}-2,254 * * \\
(0,216)\end{array}$ & $-12,6$ \\
\hline 2do Quintil & $\begin{array}{r}0,048 \\
(0,065)\end{array}$ & 0,4 & & & $\begin{array}{r}0,169 \\
(0,106)\end{array}$ & 2,2 \\
\hline 3er Quintil & $\begin{array}{c}0,106^{*} \\
(0,065)\end{array}$ & 0,8 & $(0,108)$ & & 0,135 & 1,7 \\
\hline 4to Quintil & $\begin{array}{r}0,238 * * \\
(0,064)\end{array}$ & 2,0 & $(0,106)$ & & $0,314 * *$ & 4,3 \\
\hline 5to Quintil & $\begin{array}{r}0,539 * * \\
(0,066)\end{array}$ & 5,1 & & & $\begin{array}{r}0,617 * * \\
(0,109)\end{array}$ & 9,3 \\
\hline Escolaridad (>12 años) & $\begin{array}{r}0,688^{* *} \\
(0,047)\end{array}$ & 6,9 & $\begin{array}{r}0,876^{* *} \\
(0,043)\end{array}$ & 10,3 & $\begin{array}{r}0,674^{* *} \\
(0,081)\end{array}$ & 10,4 \\
\hline $\begin{array}{l}\text { Observaciones } \\
\text { cambiaron de comuna } \\
\%\end{array}$ & $\begin{array}{r}44586 \\
3346 \\
7,5\end{array}$ & & $\begin{array}{r}44586 \\
3346 \\
7,5\end{array}$ & & $\begin{array}{r}31375 \\
1059 \\
3,4\end{array}$ & \\
\hline McFadden R2 & 0,175 & & 0,172 & & 0,060 & \\
\hline
\end{tabular}

* Significante al $10 \%$.

** Significante al $1 \%$.

Error estándar entre paréntesis. 
3,5\% de los propietarios se mueve de comuna en la muestra) y refleja un efecto inmovilizador de la vivienda económica para los hogares beneficiarios. La especificación 3 del modelo (última columna de la Tabla $\mathrm{N}^{\circ}$ 11) calcula los efectos sobre la probabilidad de cambio de comuna sólo para los propietarios. En este caso también se observa un efecto negativo importante y significativo de la vivienda económica de 4 puntos porcentuales sobre la probabilidad de cambio.

Las otras variables incluidas también son relevantes para explicar movilidad. Como puede apreciarse en los resultados de la estimación, el estar en los quintiles superiores de ingreso aumenta la probabilidad de cambio de comuna, lo que corrobora la evidencia de la Tabla $\mathrm{N}^{\circ} 10, \mathrm{y}$ también lo hace el hecho de tener más de 12 años de escolaridad. El efecto de la edad del jefe del hogar también es significativo e indica que a mayor edad disminuye la probabilidad de cambio de comuna.

Es posible concluir que la movilidad habitacional es baja en Chile, lo cual no es un problema en la medida que refleje preferencias de los hogares. Sin embargo, el hecho de que haya un efecto inmovilizador de la vivienda económica, hace pensar que los hogares beneficiarios se encuentran "atrapados" en sus viviendas ${ }^{54}$. ¿Por qué se produce este efecto en el stock habitacional subsidiado?

La principal razón pareciera estar en la no existencia, o al menos, escaso desarrollo del mercado de viviendas económicas, es decir, hay una dificultad de los tenedores de viviendas sociales de venderlas y/o de quienes quieren comprarlas de poder hacerlo ${ }^{55}$. Este mercado no ha podido desarrollarse, como se mencionó más arriba, debido a que las viviendas que han sido objeto de un subsidio habitacional están bajo una prohibición de enajenación y de arriendo por hasta cinco años después de haber sido otorgado el subsidio. Se podría decir que los subsidios habitacionales no son parte de una "política patrimonial", es decir, de dotar de un activo o patrimonio a los hogares de modo que puedan utilizarlo a libre elección. Más bien se les otorga una vivienda específica, o un subsidio para adquirirla, la cual no tiene prácticamente usos alternativos para el hogar beneficiario. Se trata de un activo de

${ }^{54}$ De acuerdo a una encuesta realizada por Rodríguez y Sugranyes (2004) casi el $65 \%$ de los hogares encuestados y que ocupan viviendas sociales querrían moverse de sus viviendas.

${ }^{55}$ Doña, Larrañaga y Torche (2003) analizan algunas razones de por qué este mercado no se ha desarrollado. 
escasísima liquidez, lo cual le resta valor de mercado. El programa "Movilidad Habitacional" ha buscado precisamente darles algo de portabilidad a los subsidios pero no ha sido exitoso.

Una segunda razón para esto pareciera estar en la preferencia de las políticas habitacionales por subsidiar viviendas nuevas por muchos años que ha ido en desmedro del desarrollo de un mercado habitacional de viviendas de menor valor (de menos de 1.000 UF y hasta de menos de 500 UF). Y aun cuando desde hace ya bastante tiempo es posible utilizar los subsidios para la adquisición de viviendas usadas, esto no ocurre a gran escala. De acuerdo a información del MINVU, de los subsidios pagados en el SGU, en promedio el 84\% se aplicó a viviendas nuevas. En el caso de la Modalidad Libre Elección de la Vivienda Básica y Progresiva los subsidios pagados nunca fueron muchos en comparación con la Modalidad SERVIU, en la cual la misma autoridad construía las viviendas ${ }^{56}$.

Por otra parte las viviendas económicas construidas en la Modalidad SERVIU contienen o han contenido subsidios ocultos, especialmente en el valor del suelo, el cual era puesto a disposición por el propio MINVU durante bastantes años, y también a través de los créditos SERVIU, que en promedio se devolvían en un $65 \%{ }^{57}$. Con esto es imposible que las viviendas usadas, sociales o no, compitieran con las viviendas sociales nuevas. Actualmente con la supresión de los programas de construcción del propio SERVIU y de sus créditos y el cambio hacia proyectos desarrollados por EGIS dentro del Fondo Solidario de Vivienda es posible que se eliminen estos subsidios ocultos, específicamente en el caso donde las EGIS son entidades privadas. En el caso de los proyectos que son llevados a cabo por los municipios es probable que siga habiendo subsidios ocultos por un acceso preferencial de los municipios al suelo o directamente por un subsidio de una parte o de la totalidad de suelo municipal para la construcción de viviendas sociales.

Existen además costos de transacción que encarecen la movilidad de hogares de menores ingresos y viviendas de bajo costo. Estos costos pueden estar ligados a los trámites legales de inscripción y traspaso de títulos de dominio, escrituras y también costos de información. Es probable además que la necesidad de crédito para poder realizar transacciones inmobiliarias dificulte adicionalmente el cambio de

${ }^{56}$ Véase la información en el Gráfico No 4 y Tabla No 6.

${ }^{57}$ Véase nota 39. 
vivienda y la compra de viviendas por parte de hogares de menores recursos. La Cámara Chilena de la Construcción estima que estos costos ascienden a entre 2 y $4 \%$ del valor de la vivienda y que son probablemente mayores en el caso de viviendas de menor valor ${ }^{58}$. Sin embargo, sabemos poco acerca del funcionamiento de ese mercado.

Un efecto negativo adicional viene de la modalidad en que se otorgan los subsidios. Dado que el beneficiario no tiene cómo saber si recibirá o no el subsidio, no puede buscar la vivienda mientras no lo tenga. Recién entonces comienza su búsqueda. Una modalidad más automática de obtención de subsidios beneficiaría también el mercado de las viviendas usadas ${ }^{59}$. Esta propuesta no parece tan difícil de implementar para el MINVU, toda vez que en los últimos años la razón entre beneficiarios a postulantes se ha ido acercando al $100 \%{ }^{60}$. Otra posible solución a esto es entregar un subsidio adicional para quienes optan por viviendas usadas, que cubra los mayores costos de transacción e incentive a los beneficiarios a buscar viviendas usadas en vez de viviendas nuevas. Se ha planteado también el desarrollo de un mercado de arriendo de viviendas sociales, entregando subsidios para la construcción de viviendas de arriendo ${ }^{61}$. La República Federal Alemana ha usado un sistema de este tipo desde hace más de cincuenta años con éxito desde el punto de vista de proveer viviendas, pero los efectos colaterales del subsidio han sido cuantiosos ${ }^{62}$.

Más allá de estas propuestas, pareciera que ninguno de los programas habitacionales que ofrece hoy el MINVU será capaz de solucio-

${ }^{58}$ Véase CCHC (Cámara Chilena de la Construcción) (2004).

${ }^{59}$ Esto es lo que Doña, Larrañaga y Torche (2005) han llamado el "subsidio en tiempo real".

${ }^{60}$ Véase, por ejemplo, MINVU (2006), pp. 52 ss.

${ }^{61}$ Hay una propuestas de la CCHC en esta dirección. Véase CCHC (2004), p. 6 (recuadro 1).

${ }^{62}$ Sobre el sistema de subsidio habitacional alemán, véanse los trabajos de Simian (2000) y Simian (2004). Este sistema puede funcionar entregando un subsidio, por ejemplo, a una sociedad inmobiliaria que es propietaria de las viviendas y las arrienda a hogares de menores recursos, que pueden definirse como hogares con un ingreso familiar hasta un cierto límite. En el caso alemán la obligación de arrendar a hogares de menores recursos es por un tiempo predeterminado, por lo general, entre 15 y 20 años. Luego las viviendas pueden ser arrendadas a cualquier persona. El problema de este tipo de sistemas de subsidio es que es difícil para la autoridad asegurarse de que las viviendas estén arrendadas a los hogares que se quiere beneficiar. En Alemania hubo continuos problemas de viviendas sociales arrendadas a hogares que sobrepasaban los límites de ingreso familiar. El subsidio al arriendo puede solucionar algunos problemas, especialmente de calidad de las viviendas, pero trae otros aparejados que no son fáciles de solucionar. 
nar este problema. Esta situación impide que el stock de viviendas sociales existente sea aprovechado para proveer de soluciones habitacionales a nuevos hogares y evitar así tener que seguir con una continua expansión del stock habitacional.

\subsection{Calidad}

Mucho se ha discutido ya sobre lo que el propio MINVU ha llamado la "crisis de la calidad"63 de la vivienda social en Chile. En este capítulo analizamos la calidad de la vivienda en Chile con especial énfasis en la vivienda social, utilizando la información de la encuesta CASEN 2006. Nos centramos aquí en problemas de materialidad y conservación de las viviendas en zonas urbanas, subentendiendo que hay otros aspectos de la calidad como son la segregación y el hacinamiento que ya han sido abordados en secciones anteriores.

¿Qué calidad tienen las viviendas en Chile? Para medir la calidad de la vivienda es posible utilizar la encuesta CASEN, la cual incluye información respecto de los materiales predominantes en el piso, muros y techo de las viviendas e información acerca del estado de conservación de esos materiales. Esto último considera tres categorías: "bueno", "aceptable" y "malo". En base a esas tres categorías de conservación de materiales se construyó un índice de conservación de las viviendas a través del uso de puntos. Se asignaron 2 puntos para muros, techos y pisos en estado de conservación "bueno", 1 punto para "aceptable” y 0 punto para "malo". De este modo, una vivienda que tiene muros, techo y piso en estado "bueno" tiene un índice de 6 puntos, versus 0 puntos en el caso de que las tres categorías estén en estado "malo". Adicionalmente se calculó una velocidad de deterioro de las viviendas: suponiendo que éstas al construirse tienen un estado de conservación de 6 y midiendo los años desde que el hogar ocupa esa vivienda hasta el momento de tomar la encuesta. De este modo se obtiene una cifra que indica los puntos de índice de conservación que la vivienda pierde por año. Esta cifra permite calcular también una tasa de depreciación implícita. Así por ejemplo, una vivienda que pierde 0,5 puntos por año, tendría una vida útil de 12 años y estaría depreciándose a una tasa de 8,3\% por año. Esta cifra debe tomarse con cautela ya que es posible

${ }^{63}$ Véase MINVU (2007), p. 300. 
que la fecha en que el hogar accedió a la vivienda no sea la fecha de construcción de ésta. Especialmente en el caso de las viviendas a las que se accedió sin subsidio, que fueron o compradas o heredadas, es muy probable que esto sea así. Por otra parte, la información del año de acceso que permite calcular la velocidad de deterioro sólo está disponible en el caso de los hogares propietarios, limitando así el análisis a casi 30.000 viviendas.

Dentro de la muestra el índice promedio de conservación, en zonas urbanas, es de 4,8 (sobre 6, es decir un 80\%) y la velocidad promedio de deterioro es de 0,14 (puntos por año), lo que implica una tasa de depreciación implícita de $2 \%$ y una vida útil promedio de todas las viviendas de 50 años.

Como el estado de conservación no es independiente de los materiales usados en la construcción de la vivienda se confeccionó un segundo índice de materialidad de las viviendas, considerando los materiales predominantes en muros, pisos y techos. Para simplificar la información de la CASEN se tomaron sólo dos categorías de materiales: de mayor solidez y menor solidez y se les asignó el valor 1 para mayor solidez y 0 para menor solidez ${ }^{64}$. Sumando los índices 0 ó 1 para muros, pisos y techos se obtiene un índice de materialidad de la vivienda que va de 0 a 3 . Dentro de toda la muestra el índice promedio de materiales es de 2,7 .

La Tabla $\mathrm{N}^{\circ} 12$ resume la principal información de calidad y deterioro de las viviendas. Se seleccionaron además sólo las viviendas en zonas urbanas ya que hay importantes diferencias con las de zonas rurales que hacen que la información de ambas zonas no sea comparable. Varios elementos llaman la atención. En primer lugar, la vivienda económica (sobre todo Progresiva y Básica, junto con aquellos hogares que, de acuerdo a la CASEN, han recibido "otro beneficio") no es la de peor índice de conservación, como pudiera pensarse. Las viviendas de los quintiles I a III que no han recibido subsidio están en peor estado de conservación que aquellas con subsidio de vivienda económica en

${ }^{64}$ Concretamente se consideró el valor 1 para muros de acero u hormigón armado, albañilería, tabiques forrados y adobe y el valor 0 para el resto (tabiques sin forrado, barro, materiales de desecho). En el caso de los pisos se tomó el valor 1 para pisos de radier (revestido o no) y tablas sobre vigas y el valor 0 para pisos de madera, plástico, etc., directamente sobre tierra y vivienda sin piso. Para los techos se tomó el valor 1 para techos de teja y de otros materiales con cielo interior y el valor 0 para todos los demás sin cielo interior. 
TABLA N ${ }^{\circ}$ 12: $\quad$ CALIDAD DEL STOCK HABITACIONAL EN CHILE (SÓLO ZONAS URBANAS)

\begin{tabular}{lcccccr}
\hline & $\begin{array}{c}\text { Prom. } \\
\text { Ind. } \\
\text { Conserv. } \\
\text { (ptos) }\end{array}$ & $\begin{array}{c}\text { Veloc. } \\
\text { deterioro } \\
\text { (ptos/año) }\end{array}$ & $\begin{array}{c}\text { Depreciación } \\
\text { implí́ita } \\
\text { (\%) }\end{array}$ & $\begin{array}{c}\text { Materiales } \\
\text { (ptos) }\end{array}$ & $\begin{array}{c}\text { Antigüedad } \\
\text { (años) }\end{array}$ & $\begin{array}{r}\text { Muestra } \\
\text { viviendas } \\
\text { (unidades) }\end{array}$ \\
& & & & & & \\
\hline Sin subsidio & 3,90 & 0,217 & 3,61 & 2,61 & 21,18 & 3.692 \\
I & 4,41 & 0,155 & 2,59 & 2,73 & 21,65 & 3.597 \\
II & 4,73 & 0,117 & 1,96 & 2,79 & 22,31 & 3.762 \\
III & 5,12 & 0,093 & 1,56 & 2,84 & 20,94 & 3.571 \\
IV & 5,50 & 0,052 & 0,87 & 2,93 & 18,08 & 3.279 \\
V & & & & & & \\
Subsidio Habitacional & PET & & & & & \\
I & 4,85 & 0,077 & 1,28 & 2,90 & 16,42 & 291 \\
II & 5,04 & 0,079 & 1,31 & 2,97 & 15,59 & 410 \\
III & 5,15 & 0,085 & 1,42 & 2,96 & 15,38 & 457 \\
IV & 5,47 & 0,040 & 0,67 & 3,01 & 14,89 & 488 \\
V & 5,61 & 0,050 & 0,84 & 2,95 & 15,02 & 349 \\
Vivienda Económica & & & & & & \\
I & & & & & & \\
II & 4,54 & 0,187 & 3,11 & 2,86 & 12,66 & 1.152 \\
III & 4,90 & 0,132 & 2,19 & 2,90 & 13,92 & 1.102 \\
IV & 4,95 & 0,126 & 2,10 & 2,92 & 15,34 & 947 \\
V & 5,17 & 0,086 & 1,43 & 3,01 & 15,24 & 658 \\
& 5,42 & 0,057 & 0,95 & 2,93 & 15,83 & 265 \\
\hline
\end{tabular}

Las cifras consideran sólo zonas urbanas.

Escala índice de conservación: 1 a 6 (máx.). Escala indice materiales: 1 a 3 (máx.).

${ }^{(1)}$ Básica, progresiva, FSV, VSDSD.

Fuente: Elaboración propia en base a CASEN 2006.

los mismos quintiles, y también su materialidad es peor y se deterioran más rápido. Éstas son buenas noticias para la política habitacional chilena ya que si comparamos hogares de los mismos quintiles, aquellos que han recibido subsidio tienen viviendas con mejores materiales y que están en mejor estado de conservación. No sorprende, por otro lado, que el peor estado de conservación y materialidad de las viviendas sin subsidio está en directa relación con la edad de las viviendas. Como puede verse en la tabla, las viviendas que no han sido objeto de subsidios son más antiguas. En el caso del primer quintil de ingreso, las viviendas son, en promedio, ocho años más viejas que en el caso de las viviendas económicas ocupadas por hogares del mismo quintil de ingreso. 
En una primera mirada y con estos datos no hay evidencia de que las viviendas con subsidio sean de peor calidad. Por el contrario, las viviendas de subsidio, tanto económicas como aquellas que han sido compradas con subsidio habitacional, son de mejor calidad, en cuanto a los materiales y el estado de conservación, que aquellas viviendas que no han sido objeto de subsidios. Esto se cumple, al menos, al comparar viviendas ocupadas por hogares en el mismo quintil de ingreso. Por otro lado, las viviendas económicas presentan una mayor velocidad de deterioro que las viviendas del subsidio habitacional. Ambas, en todo caso, se deterioran más lento que las viviendas sin subsidio en los quintiles de ingreso similares.

Dada la antes mencionada segregación de los hogares beneficiarios de la política habitacional, cabe preguntarse si la mayor calidad encontrada de las viviendas va aparejada de una "peor localización” de las mismas, es decir, cabe preguntarse si existiría un trade off entre calidad y localización, produciéndose el efecto de que las viviendas sociales sean mejores pero estén más alejadas del comercio, lugares de trabajo, etc. Lamentablemente la encuesta CASEN 2006 no contiene información de cuán buena o mala es la localización de las viviendas de los hogares encuestados. Sin embargo, para las comunas del Gran Santiago es posible hacer el siguiente ejercicio: se extrajo la información contenida en la Tabla $\mathrm{N}^{\circ} 12$ y se agregó la distancia promedio entre la comuna donde se encuentran las viviendas y el centro de Santiago como una variable proxie de localización. Se trata de una evidencia muy preliminar y sólo para viviendas que se encuentran en comunas del Gran Santiago, reduciéndose la muestra a algo menos de 5.000 viviendas (contra 24.000 del análisis anterior). Los resultados aparecen en la Tabla $\mathrm{N}^{\circ} 13$. Se mantiene la diferencia de calidad entre las viviendas sin y con subsidio para los primeros cuatro quintiles de ingreso, pero es bastante menor que para la muestra completa. La tabla muestra que hay una mayor distancia promedio al centro de la ciudad de las viviendas con subsidio que de las sin subsidio. Esto es especialmente notorio en el caso de la vivienda económica, donde las viviendas económicas del primer quintil de ingreso están, en promedio, tres kilómetros más lejos del centro que las viviendas sin subsidio del mismo quintil. De acuerdo a esta evidencia, que es acotada a viviendas en el Gran Santiago, podría haber un cierto trade off entre calidad y localización, es decir, las viviendas de subsidio tienen una calidad superior 


\begin{tabular}{|c|c|c|c|c|c|c|c|}
\hline & $\begin{array}{l}\text { Prom } \\
\text { Ind } \\
\text { Conserv } \\
\text { (ptos) }\end{array}$ & $\begin{array}{c}\text { Veloc } \\
\text { deterioro } \\
\text { (ptos/año) }\end{array}$ & $\begin{array}{c}\text { Depre- } \\
\text { ciación } \\
\text { implícita } \\
\text { (\%) }\end{array}$ & $\begin{array}{l}\text { Materiales } \\
\text { (ptos) }\end{array}$ & $\begin{array}{l}\text { Antigüe- } \\
\text { dad } \\
\text { (años) }\end{array}$ & $\begin{array}{c}\text { Distancia } \\
\text { promedio } \\
\text { al centro } \\
(\mathrm{kms})^{(2)}\end{array}$ & $\begin{array}{c}\text { Muestra } \\
\text { viviendas } \\
\text { (unida- } \\
\text { des) }\end{array}$ \\
\hline \multicolumn{8}{|c|}{ Sin subsidio } \\
\hline I & 4,36 & 0,128 & 2,13 & 2,76 & 23,73 & 14,92 & 371 \\
\hline II & 4,76 & 0,132 & 2,20 & 2,87 & 22,88 & 14,88 & 512 \\
\hline III & 5,07 & 0,089 & 1,48 & 2,89 & 23,63 & 14,70 & 721 \\
\hline IV & 5,34 & 0,056 & 0,94 & 2,94 & 21,96 & 12,88 & 830 \\
\hline V & 5,71 & 0,028 & 0,47 & 3,01 & 16,88 & 12,31 & 1.104 \\
\hline \multicolumn{8}{|c|}{ Subsidio Habitacional y PET } \\
\hline I & 4,72 & 0,088 & 1,46 & 2,93 & 17,41 & 13,92 & 46 \\
\hline II & 5,09 & 0,076 & 1,26 & 3,14 & 15,31 & 15,37 & 88 \\
\hline III & 5,22 & 0,157 & 2,62 & 3,13 & 14,29 & 16,75 & 112 \\
\hline IV & 5,43 & 0,032 & 0,54 & 3,09 & 17,02 & 14,91 & 140 \\
\hline V & 5,57 & 0,025 & 0,41 & 2,99 & 18,02 & 15,68 & 84 \\
\hline \multicolumn{8}{|c|}{ Vivienda Económica ${ }^{(1)}$} \\
\hline I & 4,75 & 0,142 & 2,36 & 2,93 & 15,27 & 17,86 & 153 \\
\hline II & 4,98 & 0,084 & 1,40 & 2,97 & 17,33 & 16,97 & 178 \\
\hline III & 5,15 & 0,075 & 1,25 & 2,93 & 19,34 & 16,27 & 183 \\
\hline IV & 5,29 & 0,059 & 0,98 & 3,17 & 17,96 & 15,17 & 157 \\
\hline V & 5,50 & 0,026 & 0,44 & 2,98 & 20,02 & 16,11 & 62 \\
\hline
\end{tabular}

Las cifras consideran sólo las comunas del Gran Santiago.

Escala índice de conservación: 1 a 6 (máx.). Escala índice materiales: 1 a 3 (máx.).

(1) Básica, progresiva, FSV, VSDSD.

(2) Información de distancia al centro en Galetovic y Poduje (2006), p. 13.

Fuente: Elaboración propia en base a CASEN 2006.

pero estarían ubicadas en peores localizaciones, medido aquí como mayor distancia al centro de la ciudad.

¿Lograrán mejorar los nuevos programas de subsidio la calidad de las viviendas? Es difícil decirlo todavía. Concretamente en el caso del Fondo Solidario de la Vivienda (junto con la Vivienda Social Dinámica sin Deuda), que es lo que ha reemplazado a la Vivienda Básica y Progresiva, es positivo el hecho de que se haya eliminado el rol constructor del SERVIU y la construcción sea llevada a cabo por municipios, que son más cercanos a las necesidades de los hogares más afectados, y por cooperativas y otras entidades gestoras. Sin embargo, al ser los subsidios y el tope máximo de las viviendas bastante bajos, es poco probable que se puedan tener mejoras sustanciales en la calidad. 
Por otra parte y mirando las cifras de la Tabla 12, lo que se necesita es una política que permita recuperar el stock existente que está en malas condiciones y deteriorándose rápidamente. Es decir, se necesita probablemente un mayor énfasis en programas como el de Renovación Urbana y del Conservación de Patrimonio Histórico y menos en los programas enfocados a expandir el stock habitacional. Los efectos del terremoto de febrero de 2010 acentuarán sin duda esta necesidad.

\section{Conclusiones}

En las secciones anteriores se ha mostrado que Chile ha avanzado mucho en materia habitacional en los últimos cuarenta años. El stock habitacional ha crecido en mayor proporción que la población y a la par con el número de hogares. El déficit habitacional se ha podido reducir y han disminuido también los niveles de hacinamiento en las viviendas. También el número de viviendas permanentes, es decir aquellas con mejor materialidad, aumentó sustantivamente en los últimos años. La política habitacional ha jugado un papel preponderante en estos cambios y ha logrado que una gran mayoría de los hogares en Chile sea propietario de su vivienda.

Persisten, sin embargo, importantes problemas que en parte han sido generados por la propia política habitacional y que urge solucionar. Uno de ellos es la segregación de hogares de menores recursos en los extremos de las zonas urbanas. Este fenómeno se ha producido por la aplicación masiva de programas de vivienda económica y, como se pudo mostrar, los programas de vivienda económica actual (específicamente el Fondo Solidario de Vivienda) no significan un camino distinto en este ámbito y corremos el riesgo de seguir segregando a muchos hogares en el país.

Existe en Chile una baja movilidad de los hogares que está asociada al hecho que la gran mayoría son propietarios y éstos se mueven menos. Sin embargo, se ha encontrado evidencia de un efecto inmovilizador adicional de la vivienda económica para los beneficiarios de esos programas habitacionales.

Hay diversos indicios de que el mercado habitacional para la vivienda de bajo precio no funciona eficientemente. Esto, en parte, es generado por la propia política habitacional y el fuerte foco de todos los 
subsidios en la vivienda nueva. Sin embargo, pareciera también haber altos costos de transacción que dificultan el movimiento de hogares en viviendas de bajo precio. No sabemos exactamente qué ocurre en este mercado y hay aquí un ámbito para investigaciones futuras.

Respecto de la calidad de las viviendas, se ha podido mostrar que, contra lo que pudiese pensarse, la vivienda social no es la vivienda de peor calidad. Las viviendas de los quintiles más bajos de ingreso (especialmente del primero) muestran los peores índices de conservación y materialidad y las tasas más altas de deterioro.

Los instrumentos de política habitacional de los cuales disponemos actualmente no parecen ser especialmente adecuados para resolver estos problemas. La política habitacional debe centrar sus esfuerzos en mejorar el funcionamiento del mercado de la vivienda de bajo precio, reenfocar sus instrumentos hacia la recuperación del stock habitacional existente e ir disminuyendo los subsidios destinados a la expansión del stock de viviendas.

\section{REFERENCIAS}

Almarza, Sergio (1997): "Financiamiento de la Vivienda de Estratos de Ingresos Medios y Bajos: La Experiencia Chilena”. CEPAL Serie de Financiamiento del Desarrollo, Nr. 46. Mayo 1997.

Bravo, Luis (1959): Chile: El Problema de la Vivienda a través de su Legislación (19061959). Santiago 1959.

Castañeda, Tarcisio (1990): Para Combatir la Pobreza: Política Social y Descentralización en Chile durante los 80. Santiago: Centro de Estudios Públicos.

Castañeda, Tarsicio y Jorge Quiroz (1986): "Las Políticas de Vivienda en Chile y su Impacto Redistributivo en 1969 y 1980-1983”. Estudios Públicos, № 22.

Castillo, María José y Rodrigo Hidalgo (2007): “1906/2006. Cien Años de Política de Vivienda en Chile”. Ediciones Universidad Andrés Bello. Serie Arquitectura Nr. 1. Santiago, noviembre 2007.

Cámara Chilena de la Construcción (2004): "El Rol de la Movilidad Habitacional en la Nueva Política de Vivienda”. Fundamenta Nr. 14. Cámara Chilena de la Construcción. Enero 2004.

_ (2008): “Balance de la Vivienda en Chile”. Cámara Chilena de la Construcción. Mayo 2008.

Census Bureau (gobierno de los EE.UU.): Housing Vacancy Survey. en http:// www.census.gov/hhes/www/housing/hus/hus.html.

CEPAL (1996): La Producción de la Vivienda en América Latina y el Caribe, Santiago: Comisión Económica para América Latina y el Caribe.

Chiuri, M. Concetta y Tullio Japelli (2003): "Financial Market Imperfections and Home Ownership: A Comparative Study”. European Economic Review, Vol. 47, 2003, pp. 857-875. 
Doña, Juan E., Osvaldo Larrañaga y Arístides Torche (2003): “Movilidad Habitacional, en la Perspectiva Social, de la Ciudad y del Usuario”. Documento de Trabajo Nr. 17. Cámara Chilena de la Construcción. Octubre 2003.

Eschenburg, Rolf y José Miguel Simian (1999): “Leasing Habitacional: Wohnungsleasing in Chile”. En M. Erlei, M. Leschke y otros (editores): Beiträge zur angewandten Wirtschaftstheorie. Regensburg 1999, pp. 277-303.

Fallis, George (1983): "Housing Tenure in a Model of Consumer Choice: A Simple Diagrammatic Analysis. American Real Estate and Urban Economics Association Journal, Vol. 11, pp. 30-44.

Galetovic, Alexander e Iván Poduje (2006): “¿Quién es Santiago?” En A. Galetovic (ed.), Santiago. ¿Dónde Estamos y Hacia Dónde Vamos? Centro de Estudios Públicos 2006, pp. 3-24.

Gandelman, Néstor (2008): "Female-Headed Households and Homeownership in Latin America”. Interamerican Development Bank. Research Network Working Paper Nr. R-547. January 2008.

Gorton, Gary (2009): “The Subprime Panic”. NBER Working Paper, Nr. 14398. Octubre 2008.

Herrera, M. Soledad (2007): "Movilidad Habitacional en la Región Metropolitana de Santiago: ¿Hacia un Mayor Asentamiento Poblacional? Comparación con Datos de los Censos 1992 y 2002”. En Carlos de Mattos y Rodrigo Hidalgo (editores), Santiago de Chile. Movilidad Espacial y Reconfiguración Metropolitana. Colección Eure Libros. Serie Geo-Libros, Nr. 8. Julio 2007, pp. 69-86.

Herrera, M. Soledad y Eduardo Valenzuela (2003): "Movilidad Residencial y Movilidad Social”. En Eugenio Tironi et al. (editores), Cuánto y Cómo Cambiamos los Chilenos. Balance de una Década. Censos 1992-2002. En Instituto Nacional de Estadística. Cuadernos Bicentenario.

Hidalgo, Rodrigo (2005): "La Vivienda Social en Chile y la Construcción del Espacio urbano en el Santiago del siglo XX”. Pontificia Universidad Católica de Chile y Centro de Investigaciones Diego Barros Arana, Colección Sociedad y Cultura.

- (2007): “¿Se acabó el Suelo en la Gran Ciudad?: Las Nuevas Periferias Metropolitanas de la Vivienda Social en Santiago de Chile”. EURE (Santiago) 2007, Vol. 33, No 98, pp. 57-75.

Horst, Bettina (2008): "Déficit Habitacional: Revisión Metodológica y Evolución en el Tiempo”. Instituto Libertad y Desarrollo. Serie Informe Económico, Nr. 194, Santiago.

INE (Instituto Nacional de Estadísticas) (1992): “Censo Nacional de Población y Vivienda, Chile 1992: Resultados Generales”. Santiago: INE.

(1993): “Censos de 1970-1982: Cifras Comparativas”. Santiago: INE.

Irarrázaval, Ignacio (2001): “Tareas Necesarias para la Superación de la Pobreza. En H. Beyer y R. Vergara (editores), ¿Qué hacer ahora? Propuestas para el Desarrollo. Santiago: Centro de Estudios Públicos, pp. 113-156.

Jaffee, Dwight y Thomas Russel (1976): "Imperfect Information, Uncertainty, and Credit Rationing”. Quarterly Journal of Economics, Vol. 90, pp. 651-66.

MacDonald, Joan (1992): “Gestión del Desarrollo Social Chileno: El Sector Vivienda”. En M. Aubá (editor): Gestión del Desarrollo Social Chileno. El Primer Año del Gobierno Democrático 1990-1991. Santiago: Corporación de Promoción Universitaria, pp. 69-103. 
Melo, Pedro (1995): “Carteras Hipotecarias Estatales. Lecciones de su Generación y Gestión”. En Políticas de Financiamiento Habitacional en Chile. Santiago: Corporación de Investigación, Estudio y Desarrollo de la Seguridad Social (CIEDESS), pp. 123-153.

MINVU (2004): “En Déficit Habitacional en Chile. Medición de Requerimientos de Vivienda y su Distribución Espacial”. Ministerio de Vivienda y Urbanismo. Santiago, noviembre 2004.

(2006): Informativo Estadístico No 283, Noviembre-Diciembre 2006.

Santiago: MINVU, División Técnica de Estudio y Fomento Habitacional, Departamento de Estadísticas.

(2007): “Un Siglo de Políticas de Vivienda y Barrio”. Ministerio de Vivienda y Urbanismo. Santiago.

OECD (2004): “OECD Economic Outlook”. October 2004.

Petermann, Alexandra (2006): “¿Quién Extendió Santiago? Una Breve Historia del Límite Urbano”. En A. Galetovic (ed.), Santiago. ¿Dónde Estamos y Hacia Dónde Vamos? Centro de Estudios Públicos, pp. 180-230.

Ravinet, Jaime (2004): "La Política Habitacional Chilena: Alternativas de Acceso a la Vivienda para las Familias Más Pobres”. Boletín del Instituto de la Vivienda, Vol. 19, No 050 , pp. 132-147.

Rodríguez, Alfredo y Ana Sugranyes (2004): “El Problema de Vivienda de los 'Con Techo’”. En EURE (Santiago), Vol. 30, № 91, pp. 53-65.

- (2005a): "Vivienda Social y Violencia Intrafamiliar: Una Relación Inquietante. ¿Una Política Social que Genera Nuevos Problemas Sociales?”. INVI, Vol. 20, No 053, pp. 11-19.

(2005b): “Mejorar el Stock de Vivienda Social en Chile”. En A. Rodríguez y A. Sugranyes (ed.), Los Con Techo. Un Desafío para la Política de Vivienda Social. En SUR Corporación de Estudios Sociales y Educación, pp. 199-217.

Sabatini, Francisco, Gonzalo Cáceres y Jorge Cerda (2001): "Segregación Residencial en las Principales Ciudades Chilenas: Tendencias de las Tres Últimas Décadas y Posibles Cursos de Acción”. EURE (Santiago), Vol. 27, Nº 82, pp. 21-42.

Simian, José Miguel (2000): Eigentumsorientierte Wohnungspolitik in Deutschland und Chile. Kooperations- und Genossenschaftswissenschaftliche Beiträge. Institut für Genossenschaftswesen der Universität Münster, Münster.

(2004): "Política Habitacional en Chile y Alemania”. Documentos de Trabajo DT-04-06, ESE Escuela de Negocios de la Universidad de los Andes. Diciembre 2004.

StBA (2007): Statistisches Bundesamt, Bautätigkeit und Wohnungen. Diciembre 2007.

Stiglitz, Joseph y A. Weiss (1981): “Credit Rationing in Markets with Imperfect Information”. American Economic Review, Vol. 71, 1981, pp. 393-410.

Tokman, Andrea (2006): "El MINVU, la Política Habitacional y la Expansión Excesiva de Santiago”. En A. Galetovic (ed.), Santiago. ¿Dónde Estamos y Hacia Dónde Vamos? Centro de Estudios Públicos 2006, pp. 489-522.

Torche, Arístides (2000): “Pobreza, Necesidades Básicas y Desigualdad: Tres Objetivos para una sola Política Social”. En: La Transformación Económica en Chile. Larraín, F. y R. Vergara (editores). Centro de Estudios Públicos. Marzo 2000, pp. 543-604. 